\title{
Trace Fear Conditioning Differentially Modulates Intrinsic Excitability of Medial Prefrontal Cortex-Basolateral Complex of Amygdala Projection Neurons in Infralimbic and Prelimbic Cortices
}

\author{
[CChenghui Song, ${ }^{1}$ Vanessa L. Ehlers, ${ }^{1}$ and James R. Moyer, Jr. ${ }^{1,2}$ \\ Departments of ${ }^{1}$ Psychology and ${ }^{2}$ Biological Sciences, University of Wisconsin-Milwaukee, Milwaukee, Wisconsin 53201
}

\begin{abstract}
Neuronal activity in medial prefrontal cortex (mPFC) is critical for the formation of trace fear memory, yet the cellular mechanisms underlying these memories remain unclear. One possibility involves the modulation of intrinsic excitability within mPFC neurons that project to the basolateral complex of amygdala (BLA). The current study used a combination of retrograde labeling and in vitro whole-cell patch-clamp recordings to examine the effect of trace fear conditioning on the intrinsic excitability of layer $5 \mathrm{mPFC}-\mathrm{BLA}$ projection neurons in adult rats. Trace fear conditioning significantly enhanced the intrinsic excitability of regular spiking infralimbic (IL) projection neurons, as evidenced by an increase in the number of action potentials after current injection. These changes were also associated with a reduction in spike threshold and an increase in $h$ current. In contrast, trace fear conditioning reduced the excitability of regular spiking prelimbic (PL) projection neurons, through a learning-related decrease of input resistance. Interestingly, the amount of conditioned freezing was (1) positively correlated with excitability of IL-BLA projection neurons after conditioning and (2) negatively correlated with excitability of PL-BLA projection neurons after extinction. Trace fear conditioning also significantly enhanced the excitability of burst spiking PL-BLA projection neurons. In both regions, conditioning-induced plasticity was learning specific (observed in conditioned but not in pseudoconditioned rats), flexible (reversed by extinction), and transient (lasted $<10 \mathrm{~d}$ ). Together, these data suggest that intrinsic plasticity within mPFC-BLA projection neurons occurs in a subregion- and cell-type-specific manner during acquisition, consolidation, and extinction of trace fear conditioning.
\end{abstract}

Key words: amygdala; associative learning; consolidation; extinction; medial prefrontal cortex; memory

Significance Statement

Frontal lobe-related function is vital for a variety of important behaviors, some of which decline during aging. This study involves a novel combination of electrophysiological recordings from fluorescently labeled mPFC-to-amygdala projection neurons in rats with acquisition and extinction of trace fear conditioning to determine how specific neurons change during behavior. This is the first study to demonstrate that trace fear conditioning significantly alters the intrinsic excitability of mPFC-to-amygdala projection neurons in a subregion- and cell-type-specific manner, which is also transient and reversed by extinction. These data are of broad interest to the neuroscientific community, and the results will inspire additional studies investigating the cellular mechanisms underlying circuit-specific changes within the brain as a result of associative learning and memory.

\section{Introduction}

Trace fear conditioning is an excellent paradigm for studying learning- and memory-related changes in higher-order brain re- gions such as the medial prefrontal cortex ( $\mathrm{mPFC})$ and the hippocampus (Gilmartin and Helmstetter, 2010; Song et al., 2012). During trace conditioning, the conditioned stimulus (CS) and unconditioned stimulus (US) are separated by a stimulus-free

\footnotetext{
Received June 16, 2015; revised Aug. 11, 2015; accepted Aug. 26, 2015.

Author contributions: C.S. and J.R.M. designed research; C.S. and V.L.E. performed research; C.S., V.L.E., and J.R.M. analyzed data; C.S. and J.R.M. wrote the paper.

This work was supported by a Research Growth Initiative from the University of Wisconsin-Milwaukee (J.R.M.) and NIA Grant R03-AG042814 (J.R.M.). We thank Joseph C. Aitken and Tyler Bula for technical assistance.

The authors declare no competing financial interests.
}

Correspondence should be addressed to Dr. James R. Moyer, Jr., Department of Psychology, P.0. Box 413, University of Wisconsin-Milwaukee, Milwaukee, WI 53201. E-mail: jrmoyer@uwm.edu.

C. Song's present address: Department of Neuroscience, The Scripps Research Institute, Jupiter, FL 33458. DOl:10.1523/JNEUROSCI.2329-15.2015

Copyright $\odot 2015$ the authors $\quad 0270-6474 / 15 / 3513511-14 \$ 15.00 / 0$ 
trace interval. Acquisition of trace conditioning is a declarative task that requires the conscious awareness of the CS-US contingency. In contrast, acquisition of a delay paradigm (where the CS and the US temporally overlap or are contiguous) is a nondeclarative task that does not require conscious awareness of the CS-US contingency (Clark and Squire, 1998; Knight et al., 2006; Weike et al., 2007). Thus, studying the cellular mechanisms underlying trace fear conditioning may lay the foundation for understanding not only the control of emotional memory but also other types of declarative memory.

The enhancement of intrinsic excitability (intrinsic plasticity) may underlie some types of associative learning (Moyer et al., 1996; Kaczorowski et al., 2012; Song et al., 2012; Sehgal et al., 2013, 2014). Previous studies suggest that the firing activity in both infralimbic (IL) and prelimbic (PL) subregions of $\mathrm{mPFC}$ is critical for acquisition of trace fear conditioning (Han et al., 2003; Runyan et al., 2004; Blum et al., 2006; Gilmartin and Helmstetter, 2010; Gilmartin et al., 2013). Although previous studies suggest that delay fear conditioning suppresses the intrinsic excitability of IL neurons (Santini et al., 2008; Santini and Porter, 2010), little is known regarding how trace fear conditioning affects the intrinsic excitability of mPFC neurons. Thus, the current study was performed to investigate how trace fear conditioning affects the intrinsic excitability of mPFC neurons.

Interestingly, the $\mathrm{mPFC}$ has reciprocal projections to a variety of cortical and subcortical brain regions including the basolateral complex of amygdala (BLA; Hurley et al., 1991; Vertes, 2004; Gabbott et al., 2005). Each type of projection neuron within $\mathrm{mPFC}$ displays distinct morphological and electrophysiological properties (Mason and Larkman, 1990; DeFelipe and Farinas, 1992; Larkman et al., 1992; Hattox and Nelson, 2007; Dembrow et al., 2010). Thus, learning may change the physiological properties of mPFC neurons in a circuit-specific manner. For example, olfactory fear conditioning excites those IL neurons that receive monosynaptic inputs from the BLA (Laviolette et al., 2005) as well as those neurons that project to the nucleus accumbens, but not the neurons that project to the contralateral mPFC (McGinty and Grace, 2008). In addition, our recent study also suggests that the mPFC neurons display distinct electrophysiological properties in a layer- and subregion-specific manner (Moyer and Song, 2014). Thus, the current study investigated how trace fear conditioning affects the intrinsic excitability of mPFC-BLA projection neurons by injecting a retrograde tracer into the basolateral nucleus of amygdala, which is an area critical for fear conditioning and extinction (LeDoux, 2000). The data suggest that trace fear conditioning transiently changes the in-
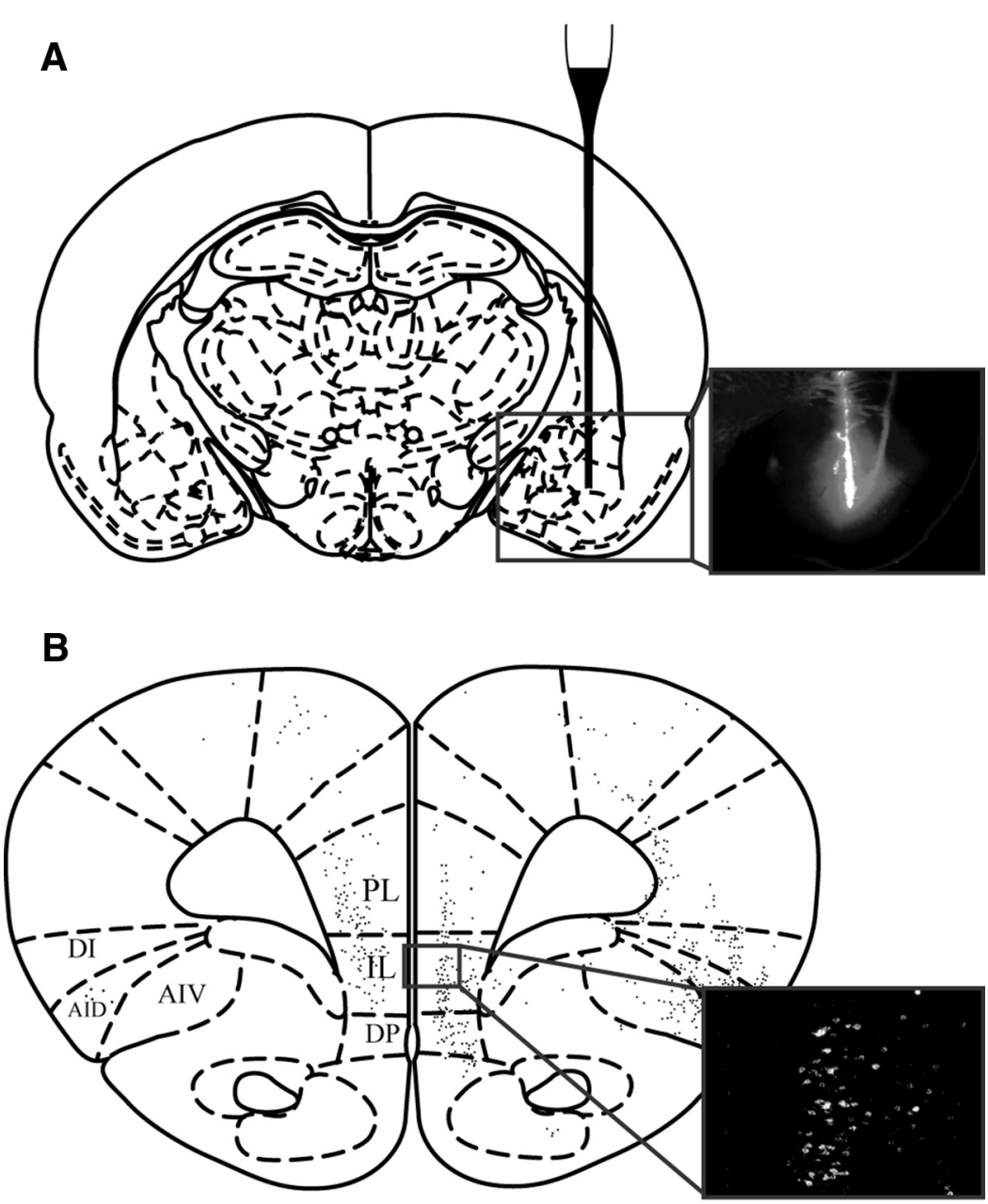

Figure 1. Unilateral infusion of a retrograde tracer into BLA was used to characterize the electrophysiological properties of mPFC-BLA projection neurons. $\boldsymbol{A}$, Schematic diagram of a rat coronal section [illustration modified from Paxinos and Watson (1998), reprinted with permission] showing that a glass pipette was used for the unilateral infusion of red fluorescent microspheres section showing the distribution of fluorescently labeled cortico-BLA projection neurons [illustration modified from Paxinos and (1998), reprinted with permission]. Each mark represents one neuron. In the ipsilateral hemisphere, intense distribution coamygdala projection neurons were primarily distributed within the mPFC. Inset, Representative fluorescent image showing the fluorescently labeled neurons in the IL subregion. AID, Agranular insular cortex, dorsal part; AIV, agranular insular cortex, ventral part; DI, dysgranular insular cortex; DP, dorsal peduncular cortex; IL, infralimbic cortex; PL, prelimbic cortex.

trinsic excitability of layer $5 \mathrm{mPFC}-\mathrm{BLA}$ projection neurons in a subregion- and cell-type-specific manner.

\section{Materials and Methods}

Subjects. Subjects were 49 adult male F344 rats (5.0 \pm 0.1 months old). Rats were maintained in an AAALAC (Association for Assessment and Accreditation of Laboratory Animal Care) accredited facility on a $14 \mathrm{~h}$ light $/ 10 \mathrm{~h}$ dark cycle and housed individually with ad libitum access to food and water. Procedures were conducted in accordance with the University of Wisconsin-Milwaukee Animal Care and Use Committee and NIH guidelines.

Retrobeads infusion. All rats received a unilateral pressure infusion of a red fluorescent retrograde tracer (Retrobeads, Lumafluor) into the basolateral nucleus of the amygdala (relative to bregma: $-3 \mathrm{~mm}$ anteroposterior, $\pm 5 \mathrm{~mm}$ mediolateral, $-8.3 \mathrm{~mm}$ dorsoventral; Fig. $1 \mathrm{~A}$ ), with a stereotaxic apparatus and under deep anesthetization. The infusion was made with glass pipettes $(20-40 \mu \mathrm{m})$ pulled from borosilicate glass (VWR micropipettes) using a Sutter Instrument P97 puller. The pipette was connected to a $2 \mu \mathrm{l}$ syringe (Hamilton) driven by an infusion pump (model 975; Harvard Apparatus). The infusion lasted 5-10 min, and the 
A

\begin{tabular}{|c|c|c|c|c|}
\hline \multirow{2}{*}{ Groups } & Day 1 & Day 2-3 & Day 4 & or Day 11 \\
\hline & CONDITIONING & EXTINCTION & \multicolumn{2}{|c|}{ TEST } \\
\hline NAÏVE & - & - & - & $\downarrow$ \\
\hline PSEUDO & $10 \mathrm{CS}$ and $10 \mathrm{US}$ & - & CS probe & $\downarrow$ \\
\hline TRACE & $10 \mathrm{CS}-\mathrm{US}$ & - & CS probe & $\downarrow$ \\
\hline TRACE-RET & $10 \mathrm{CS}-\mathrm{US}$ & - & - & CS probe \\
\hline EXT & $10 \mathrm{CS}-\mathrm{US}$ & $10 \mathrm{CS}$ alone & CS probe & $\downarrow$ \\
\hline EXT-RET & $10 \mathrm{CS}-\mathrm{US}$ & $10 \mathrm{CS}$ alone & - & CS probe \\
\hline
\end{tabular}

B

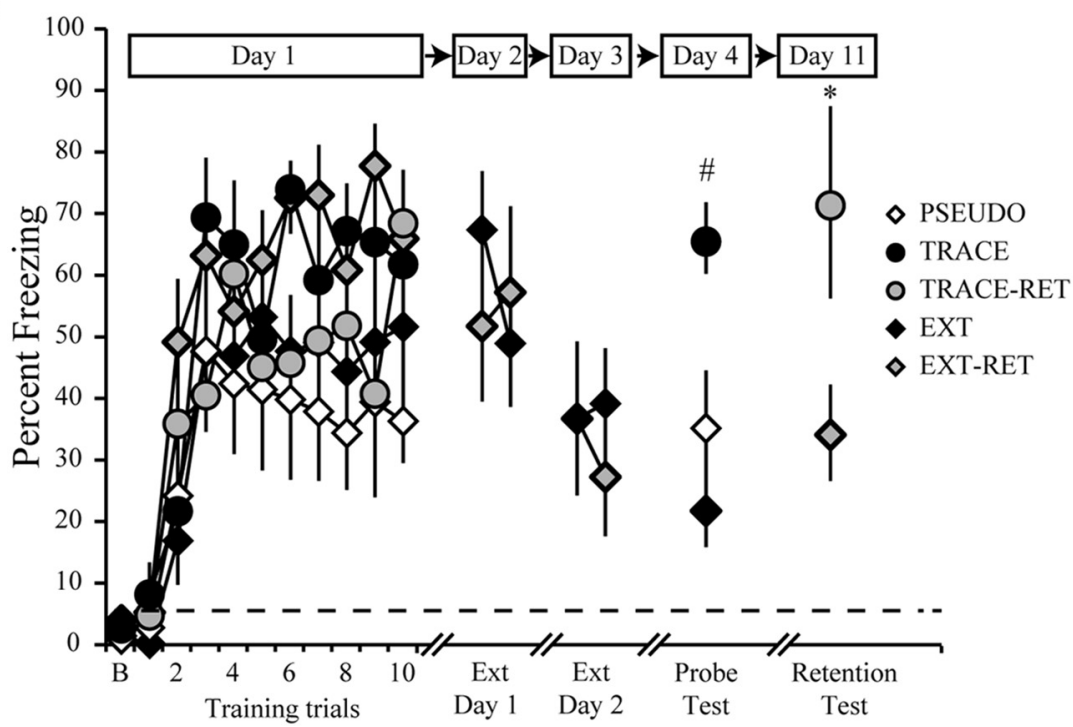

Figure 2. Experimental design and behavioral performance during acquisition and extinction of trace fear conditioning. $A$, Experimental design. Rats received one 10-trial session of trace fear conditioning or pseudoconditioning on day 1. EXT and EXT-RET rats received extinction on days $2-3$ in a novel context. TRACE, PSEUDO, and EXT rats received a brief CS-alone probe test on day 4. TRACE-RET and EXT-RET rats received the probe test on day 11 in the extinction context. Immediately after the last behavior test, brain slices were prepared for electrophysiological studies. NAIVE rats remained in their home cages throughout the experiment. $B$, Behavioral fear responses of the rats in the various groups during conditioning, extinction (first 2 trials), and testing. During conditioning, all rats displayed a rapid increase in freezing levels during the first three trials and then maintained elevated freezing levels. A repeated-measures ANOVA of percentage freezing revealed a significant main effect of training trials $\left(F_{(9,306)}=19.5, p<\right.$ 0.01; Greenhouse-Geisser corrected) and a significant effect of group $\left(F_{(4,34)}=3.2, p<0.05\right)$ but no significant group $\times$ training trial interaction $\left(F_{(36,306)}=1.1, p=0.34\right.$; Greenhouse-Geisser corrected). During the probe test on day 4 , all rats displayed comparable levels $\left(F_{(2,26)}=1.51, p=0.24\right)$ of freezing during baseline (dashed line indicates the average baseline freezing of all groups). In contrast, TRACE rats froze significantly more than both PSEUDO and EXT rats during the trace interval after the offset of the $C S\left(F_{(2,24)}=10.6, p<0.01\right)$. On day 11, TRACE-RET rats froze significantly more than EXT-RET rats during the trace interval $\left(F_{(1,10)}=5.37, p<0.05\right)$.

pipette was withdrawn $10 \mathrm{~min}$ after infusion. A total volume of $0.1-0.3$ $\mu$ l of red Retrobeads was infused into BLA.

Fear conditioning chambers. Trace fear conditioning was conducted in Plexiglas and stainless steel chambers $(30.5 \times 25.4 \times 30.5 \mathrm{~cm}$; Coulbourn Instruments), each located within a separate soundattenuating box. Each chamber was rectangular and had a standard grid floor consisting of 26 parallel steel rods $(5 \mathrm{~mm}$ diameter and 6 $\mathrm{mm}$ spacing). The floor was connected to a precision adjustable shock generator (Coulbourn Instruments) for delivery of a scrambled footshock US. Within the sound-attenuating box, a ventilation fan produced a constant background noise of $\sim 58 \mathrm{~dB}$ (measured by a sound-level meter, A scale; model 33-2050; Realistic). Each chamber was illuminated by a miniature incandescent white lamp ( $28 \mathrm{~V}$, type 1819 ; illumination 1.1 lux) and was wiped with a $5 \%$ ammonium hydroxide solution before each training session. During training, the room lights were left on (illumination, 20.9 lux) for the entire session.

Extinction and CS testing chambers. Two additional Plexiglas chambers served as a novel context for the auditory cue tests. These chambers were located within their own separate sound-attenuating boxes within the same room. The test chambers were physically distinct from the training chambers in that they were octagonal (instead of rectangular), their floors were black-painted Plexiglas (instead of stainless steel grid bars), and they were illuminated with infrared light (instead of incandescent lamps). In addition, their floors had an array of holes drilled into them. Before placing rats into the testing chambers, fresh bedding was added to the bottom tray beneath the floor, and the chamber walls were wiped with $2 \%$ acetic acid to provide a background odor distinctive from that used during training. The room lights were turned off (illumination, 0.2 lux) for the entire testing session.

Fear conditioning and extinction. After a minimum of $7 \mathrm{~d}$ of recovery from surgery, rats were handled for at least 1 week before they were randomly assigned to naive (NAIVE, $n=$ 10), pseudoconditioned (PSEUDO, $n=8$ ), trace fear conditioned (TRACE, $n=9$ ), trace fear conditioned-retention (TRACE-RET, $n=3)$, trace fear conditioned-extinction (EXT, $n=10$ ), or trace fear conditioned extinction-retention (EXT-RET, $n=9$ ) groups as summarized in Figure 2A. On day 1, TRACE, TRACE-RET, EXT, and EXT-RET rats received one 10-trial session of auditory trace fear conditioning using a $15 \mathrm{~s} \mathrm{CS} \mathrm{(80} \mathrm{dB} \mathrm{white}$ noise), followed by a $30 \mathrm{~s}$ trace interval (stimulus-free period) and a $1 \mathrm{~s}$ footshock US (1.0 mA). A long (5.2 min $\pm 20 \%)$ intertrial interval (ITI) was used to maximize the CS and minimize background context (i.e., training chamber) conditioning (Detert et al., 2008). PSEUDO rats received the same number of CS and US presentations, but they were explicitly unpaired. Naive rats remained in their home cages throughout the experiment. On days 2-3, rats in the TRACE, TRACE-RET, and PSEUDO groups remained in their home cages, whereas EXT and EXT-RET rats received two consecutive extinction sessions (10 CSalone presentations; 1 session per day) in a novel context. These sessions were identical to conditioning except no US was presented. After each extinction session, rats were returned to their home cages $2 \mathrm{~min}$ after the last extinction trial.

Behavioral testing. Twenty-four hours after extinction (day 4), PSEUDO, TRACE, and EXT rats received a brief CS test session in the extinction context. TRACE-RET and EXT-RET rats received the CS test on day 11. During this behavioral test, rats were first allowed to explore the new chamber for $2 \mathrm{~min}$ (baseline), followed by two $15 \mathrm{~s}$ CS presentations (2.9 min ITI), and they were removed $2 \mathrm{~min}$ after the second CS presentation. To assess memory, the amount of time spent freezing during the baseline, the CS, and the trace interval (defined as the first $30 \mathrm{~s}$ after CS offset) was measured. Consistent with our previous report (De- 
tert et al., 2008), the freezing levels during the CS were less than during the trace interval, and therefore the amount of time spent freezing during the trace interval was used as the dependent measure of fear (Fig. 2B). During the probe test, the percentage freezing during the trace interval after each CS presentation was averaged and used as the measurement of fear memory.

Analysis of behavioral data. A remote CCTV video camera (model WV-BP334; Panasonic), mounted to the top of each behavioral chamber, was used to record the activity of each rat during training and testing. The video data were fed to a PC running FreezeFrame 2.04 (Actimetrics Software, Coulbourn Instruments). Data were analyzed using FreezeView 2.04 (Actimetrics Software) where a $1 \mathrm{~s}$ bout of immobility was scored as freezing. Freezing was defined as the absence of all movement except that required for respiration (Blanchard and Blanchard, 1969).

PFC slice preparation for electrophysiological recordings. Within $30 \mathrm{~min}$ after the CS probe tests (Fig. 2A), rats were anesthetized and decapitated by an individual blind to the training condition. The brains were quickly removed and placed into ice-cold artificial CSF (aCSF; in mM): $124 \mathrm{NaCl}, 2.8 \mathrm{KCl}$, $1.25 \mathrm{NaH}_{2} \mathrm{PO}_{4}, 2 \mathrm{CaCl}_{2}, 2 \mathrm{MgSO}_{4}, 26 \mathrm{NaHCO}_{3}$, and 20 glucose ( $\mathrm{pH} 7.5$, bubbled with $\left.95 \% \mathrm{O}_{2} / 5 \% \mathrm{CO}_{2}\right)$. Coronal slices $(300 \mu \mathrm{m})$ containing prefrontal cortex (anteroposterior, +3.2-2.2) were cut in ice-cold aCSF using a vibrating tissue slicer (VT1200; Leica). The slices were placed into individual wells of our custom slice incubation chamber (Moyer and Brown, 1998) where they remained in oxygenated aCSF at $32-36^{\circ} \mathrm{C}$ until use. The rest of the brain was then blocked, and coronal slices that contained the amygdala were prepared to confirm infusion location. The injection site was immediately verified by placing the slice on the stage of an upright microscope (Olympus BX51WI) equipped with fluorescence (see Fig. $1 A$ for a representative image). As illustrated in Figure 3, all injection sites were within the BLA (including the basal, lateral, and accessory basal nuclei) and intercalated cell masses.

For whole-cell recordings (WCRs), electrodes (5-8 M $\Omega$ ) were prepared from thin-walled capillary glass and filled with the following solution (in $\mathrm{mM}$ ): $110 \mathrm{~K}$-gluconate, $20 \mathrm{KCl}, 10$ di-Tris-P-creatine, $10 \mathrm{HEPES}$, $2 \mathrm{MgCl}_{2}, 2 \mathrm{Na}_{2} \mathrm{ATP}, 0.3 \mathrm{Na}_{2} \mathrm{GTP}$, and $0.2 \%$ biocytin, with $\mathrm{pH} 7.3$ and an osmolarity of $290 \mathrm{mOsmol}$. All chemicals were obtained from Sigma or Thermo Fisher Scientific unless noted.

Electrophysiological recordings. PFC slices were transferred to a submerged recording chamber mounted on a fluorescence-equipped Olympus BX51WI upright microscope where they were continuously perfused with oxygenated aCSF at a rate of $2 \mathrm{ml} / \mathrm{min}$ and maintained at $32-36^{\circ} \mathrm{C}$ using an in-line temperature controller (Warner Instruments). The fluorescently labeled mPFC neurons were visualized using a Texas Red epifluorescent filter set. A Hamamatsu CCD camera (Hamamatsu Camera Ltd.) was used to visualize and photograph the neuron and the brain slice for verification of the recording location. Although both layer 2/3 (L2/3) and L5 neurons project to the amygdala (Fig. 1B), we restricted our studies to L5 neurons because they are the major output neurons (Groh et al., 2010) and have electrophysiological properties that are distinctly different from L2/3 neurons (Boudewijns et al., 2013; Moyer and Song, 2014). Neurons with somata that were $\geq 400 \mu \mathrm{m}$ from the pial surface were defined as L5 neurons (Gabbott and Bacon, 1996; Perez-Cruz et al., 2007) and were recorded and analyzed. L6 was recognized as distinct from L5 because it contains a high density of fibers (Gaillard and Sauve, 1995). After fluorescently labeled neurons were identified, the microscope was switched to infrared-differential interference contrast mode to guide whole-cell recording from identified projection neurons. Data were collected from those neurons whose resting membrane potential (RMP) was more negative than $-50 \mathrm{mV}$. Series resistance was fully compensated and always monitored to ensure the stability of recording con- ditions. Cells were only accepted for analysis if the initial series resistance was $\leq 30 \mathrm{M} \Omega$ and did not change by $>30 \%$ throughout the recording period. The distribution of all recorded neurons included in this study is shown in Figure 4, $A$ (regular spiking) and $B$ (burst spiking).

Intrinsic properties of mPFC-BLA projection neurons were studied under current-clamp conditions according to the following protocols. (1) $I-V$ relationships were obtained from a series of $500 \mathrm{~ms}$ current injections (ranging from -300 to $50 \mathrm{pA}$ ) and by plotting the plateau voltage deflection against current amplitude. Neuronal input resistance $\left(R_{\mathrm{N}}\right)$ was determined from the slope of the linear fit of the portion of the $V-I$ plot where the voltage sweeps did not exhibit sags or active conductance (Fig. $4 E, G$ ). The sag ratio during hyperpolarizing membrane responses was expressed as $\left[\left(1-\Delta V_{\mathrm{ss}} / \Delta V_{\max }\right) \times 100 \%\right]$, where $\Delta V_{\mathrm{ss}}=$ $\mathrm{MP}-V_{\mathrm{ss}}$ and $\Delta V_{\max }=\mathrm{MP}-V_{\max }$ (MP is the membrane potential before the current step, $V_{\mathrm{ss}}$ is the steady-state potential at the end of the current step, and $V_{\max }$ is the peak amplitude during the first $150 \mathrm{~ms}$ of the current step). For each neuron, the sag ratio was calculated from current injections of $-300,-250$, and $-200 \mathrm{pA}$ and averaged. (2) Action potential (AP) properties, including $I_{\text {threshold }}$, were studied with an ascending series of $500 \mathrm{~ms}$ depolarizing pulses. At rheobase, neurons could be classified as either regular spikers or burst spikers (Fig. 4). Neurons that generated a single action potential at threshold or suprathreshold current injections were classified as regular spiking (RS) neurons (Moyer et al., 2002). Neurons that generated two or more action potentials riding atop the $I_{\text {threshold }}$ depolarizing current in an all-or-none fashion were classified as burst spiking (BS) neurons (Connors et al., 1982; Moyer et al., 2002). For BS neurons, AP properties were studied from the first spike. $\mathrm{AP}$ threshold $\left(\mathrm{AP}_{\text {thresh }}\right)$ was defined as the voltage when $\mathrm{dV} / \mathrm{dt}$ first exceeded $28 \mathrm{mV} / \mathrm{ms}$ (Kaczorowski et al., 2012). The AP amplitude ( $\left.\mathrm{AP}_{\mathrm{amp}}\right)$ was measured relative to the $\mathrm{AP}_{\text {thresh }}$. Action potential width $\left(\mathrm{AP}_{\text {width }}\right)$ was measured as the width at half of the AP amplitude. (3) The postburst afterhyperpolarization (AHP) was studied after a $50 \mathrm{~Hz}$ burst of 10 spikes, each of which was evoked by a 2 ms suprathreshold current injection (three times, at $20 \mathrm{~s}$ intervals). After the last action potential, the postburst AHP was measured at both the peak amplitude within the first $150 \mathrm{~ms}$ (mAHP) and at $1 \mathrm{~s}$ (sAHP). (4) Neuronal excitability was assessed by counting the number of spikes evoked in response to a series of $1 \mathrm{~s}$ depolarizing steps (range, $50-450 \mathrm{pA} ; 50 \mathrm{pA}$ increments, $20 \mathrm{~s}$ ITI; Fig. $4 F, H)$.

All recordings were obtained in current-clamp mode (holding potential $-67 \mathrm{mV}$; mean holding current, $-62 \pm 4 \mathrm{pA}$ ) using a HEKA EPC10 amplifier system (HEKA). Data were transferred to a PC computer using an ITC-16 digital-to-analog converter (HEKA Instruments). The signals 
A

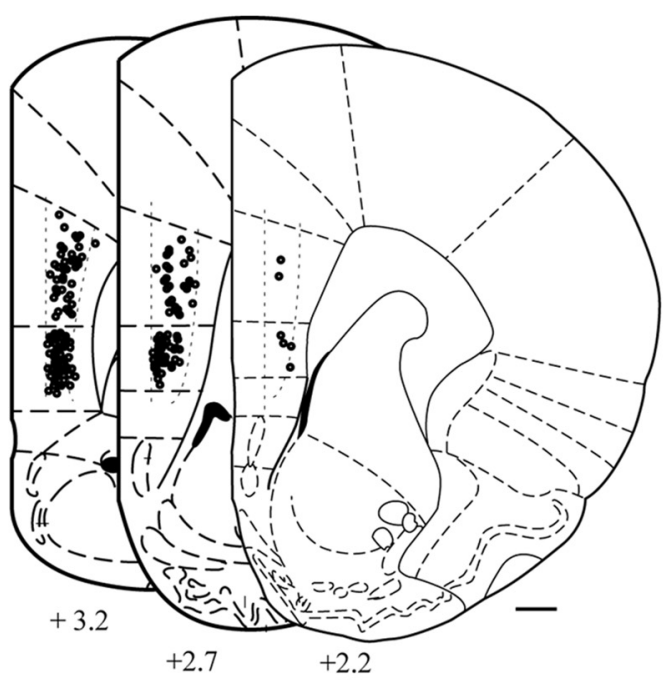

C
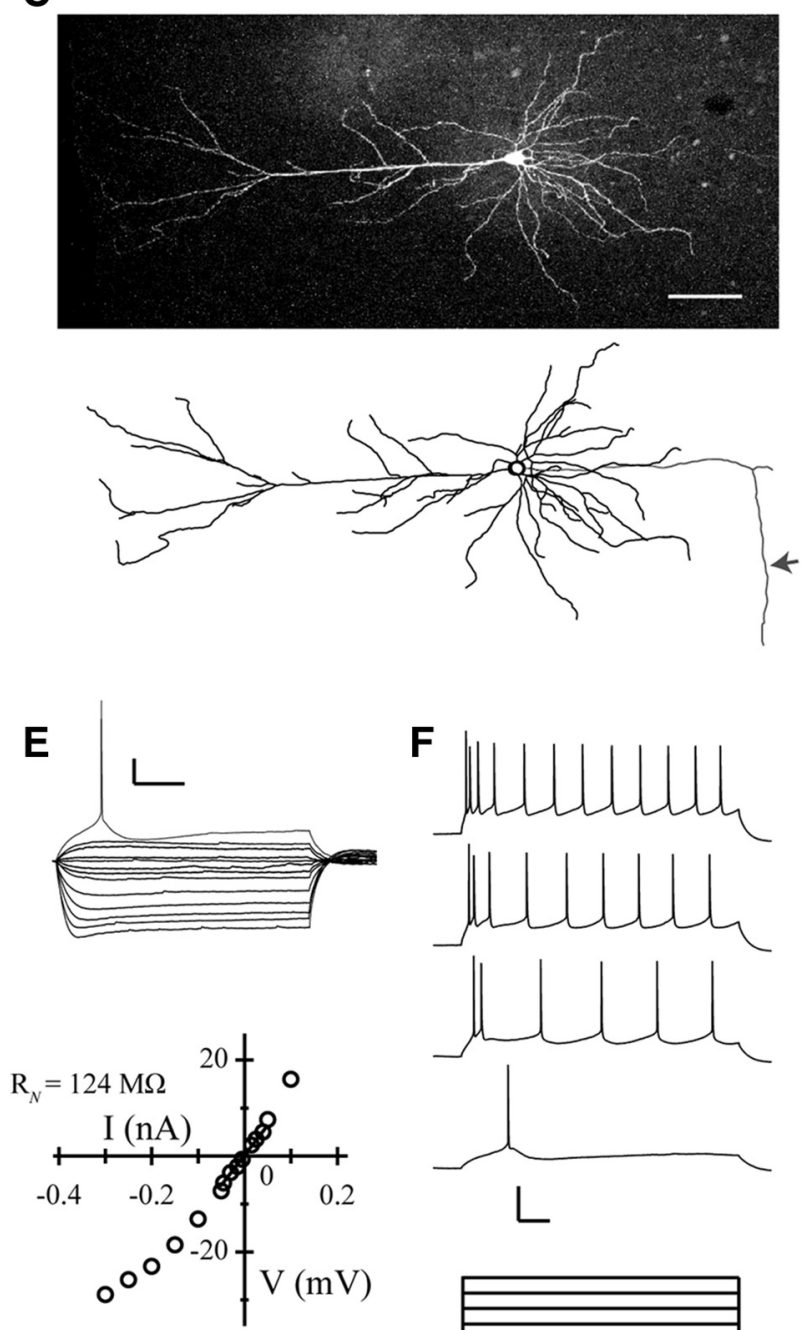

F
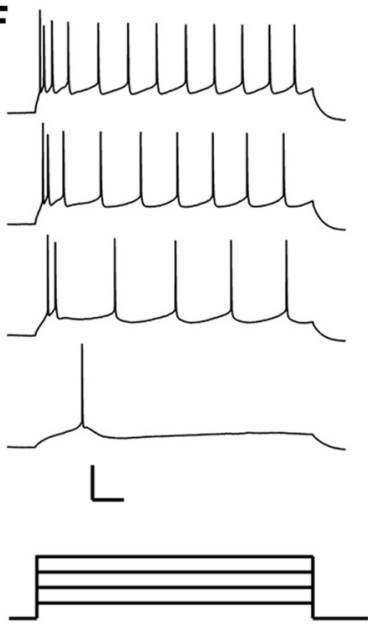

B

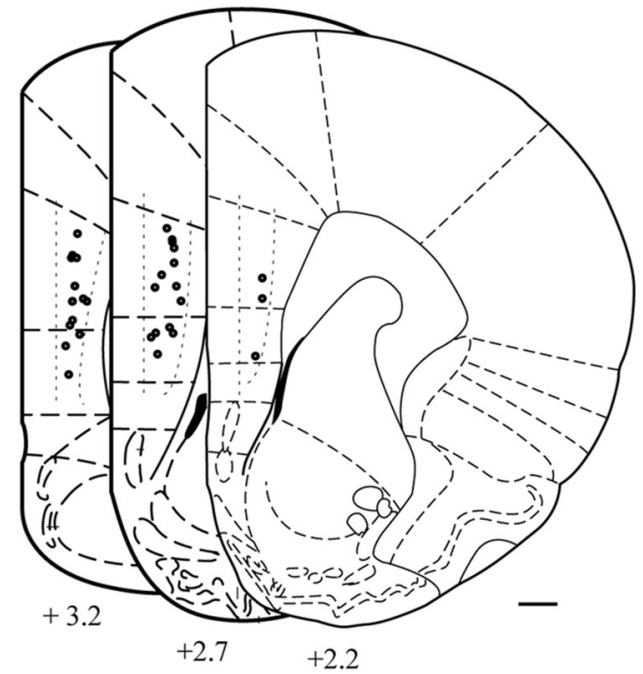

D
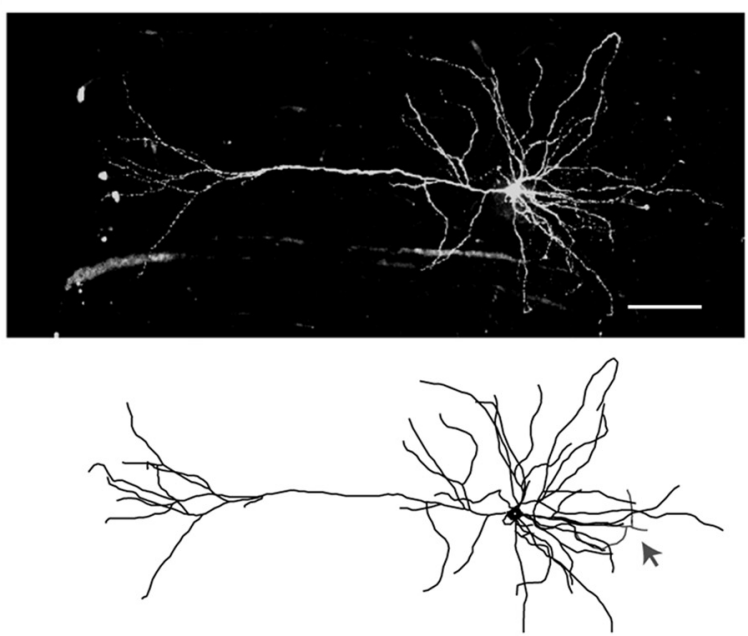

G

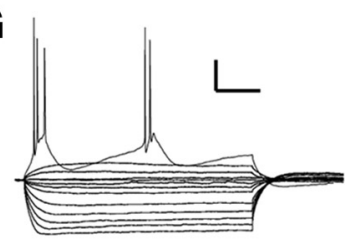

H
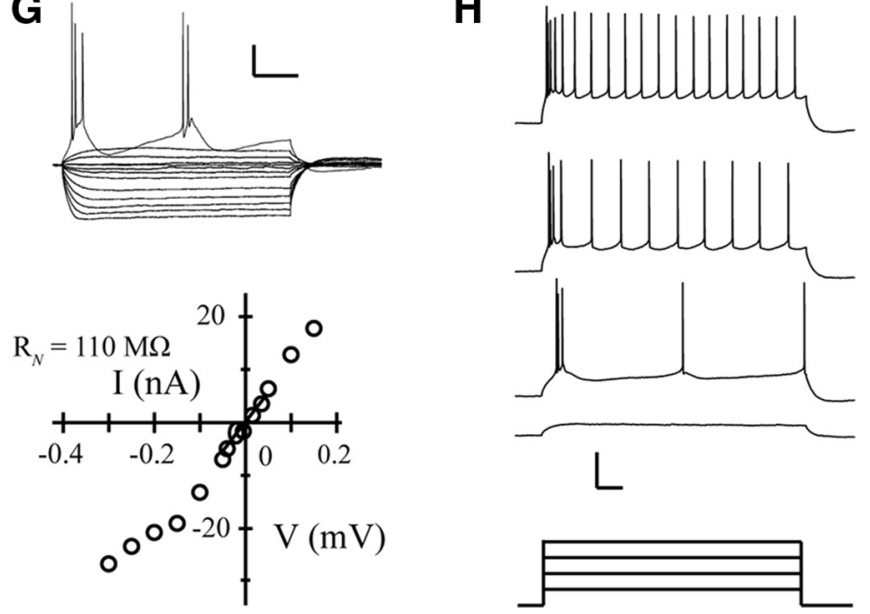

Figure 4. Two classes of $\mathrm{mPFC}-B L A$ projection neurons. $\boldsymbol{A}, \boldsymbol{B}$, Schematic diagrams of rat coronal sections (Paxinos and Watson, 1998) illustrating the distribution of all regular spiking $(\boldsymbol{A})$ and burst spiking $(\boldsymbol{B}) \mathrm{mPFC}-\mathrm{BLA}$ projection neurons obtained in this study. Neurons were recorded from either side, but all were labeled in one hemisphere for simplicity as no differences were observed. $\boldsymbol{C}, \boldsymbol{D}$, Confocal images show representative examples of regular spiking $(\boldsymbol{C})$ and burst spiking $(\boldsymbol{D}) \mathrm{mPFC}-\mathrm{BLA}$ projection neurons along with their $3 \mathrm{D}$ reconstructions. Arrows point to the axons of each cell. $\boldsymbol{E}, \boldsymbol{G}$, Voltage responses to a series of current injections and the accompanying $V-/$ plot used to measure neuronal input resistance $\left(R_{N}\right) . F, H$, Neuronal excitability was studied by injecting a series of depolarizing currents and counting the number of action potentials evoked. Scale bars: $\boldsymbol{A}, \boldsymbol{B}, 500 \mu \mathrm{m} ; \boldsymbol{C}, \boldsymbol{D}, 100 \mu \mathrm{m}$. Calibration: $\boldsymbol{E}, \boldsymbol{G}, 20 \mathrm{mV}, 100 \mathrm{~ms} ; \boldsymbol{F}, \boldsymbol{H}, 40 \mathrm{mV} / 100$ pA, $100 \mathrm{~ms}$. 
were filtered at $2.9 \mathrm{kHz}$ and digitized at $20 \mathrm{kHz}$ using Patchmaster software (HEKA). Data were analyzed off-line using Patchmaster and Igor Pro software (version 4.03; Wavemetrics). Voltages were not corrected for the liquid-liquid junction potential (approximately $+13 \mathrm{mV}$; Moyer and Brown, 2007). Recordings were made from mPFC neurons located both ipsilateral and contralateral to the BLA injection site. Physiological data were combined because no significant differences were observed.

Biocytin staining. Biocytin-filled neurons were fixed in formalin for up to 4 weeks and processed for visualization using a streptavidin Alexa Flour 488 reaction as described previously (Song et al., 2012). Briefly, the slices were incubated in $3 \% \mathrm{H}_{2} \mathrm{O}_{2} / 10 \%$ methanol for $45 \mathrm{~min}$ and washed with PBS, followed by $0.4 \%$ Triton X-100/2\% BSA for $45 \mathrm{~min}$. The slices were then incubated with 1:500 streptavidin Alexa Fluor 488 (Invitrogen) for $2 \mathrm{~h}$ in the dark and washed with PBS. They were mounted onto slides, coverslipped with Ultra Cruz Mounting Medium (Santa Cruz Biotechnology), and sealed with nail polish. The labeled neurons were visualized and photoimaged using either a fluorescence microscope (BX51WI; Olympus) or a laser-scanning confocal fluorescence microscope (FV1200; Olympus). Confocal image stacks were used for 3D reconstruction (Fig. 4C,D) using Neurolucida software (MBF Bioscience). Morphological analyses confirmed that all neurons analyzed were pyramidal neurons. Confocal images and reconstructions of representative RS and BS neurons are shown in Figures $4, C$ and $D$, respectively.

Statistical analyses. All statistical analyses were performed using IBM SPSS statistics software (version 22; SPSS). Data were analyzed using parametric statistics with two-tailed Student's $t$ test, one-way ANOVA, or repeated-measures ANOVA as appropriate. For significant main effects $(\alpha=0.05)$, a Fisher's PLSD test was used for post hoc comparisons. All data are expressed as mean \pm SEM.

\section{Results}

We examined the effect of trace fear conditioning and extinction on the intrinsic excitability of MPFC-BLA projection neurons by using a combination of retrograde labeling with whole-cell recording. All rats received a unilateral injection of fluorescently labeled microspheres before behavioral training (except NAIVE rats that received a Retrobeads injection but remained in their home cages). Rats received conditioning or pseudoconditioning on day 1 , followed by either extinction training or no treatment (i.e., they remained in their home cages) on days 2 and 3. To correlate both learning- and extinction-related changes in $\mathrm{mPFC}$ excitability with behavioral performance, rats in the TRACE, PSEUDO, and EXT groups received a brief CS-alone probe test on day 4 . To investigate whether any changes in $\mathrm{mPFC}$ excitability persisted over a prolonged period of time, rats in the TRACERET and EXT-RET groups received a probe test on day 11 (Fig. $2 A$ ). Prefrontal cortical slices were prepared within $1 \mathrm{~h}$ after the probe test, and the fluorescently labeled neurons in L5 of both IL and PL subregions were recorded. The duration from the date of surgery to the date of slicing was not significantly different between groups (mean, $30.8 \pm 2.2 \mathrm{~d} ; F_{(5,43)}=0.19, p=0.97$ ).

Analysis of behavioral performance during the trace interval indicated that all rats exhibited a rapid increase in percentage freezing during the first three trials, after which they maintained a high level of freezing throughout the remainder of the training session (Fig. 2B). However, a repeated-measures ANOVA with post hoc tests showed that PSEUDO rats froze significantly less than TRACE $(p<0.05)$ or EXT-RET $(p<0.01)$ rats. Although EXT rats froze less than EXT-RET rats $(p<0.05)$, they displayed comparable levels of freezing during the first two trials of extinction, indicating the memory of conditioned fear was comparable between the two groups. When memory was tested on day 4, rats in the TRACE, EXT, and PSEUDO groups displayed comparably low levels of baseline freezing (Fig. $2 B$, average baseline freeze is shown as a dashed line). In contrast, there was a statistically sig- nificant difference in percentage freezing during the trace interval immediately after CS offset. Post hoc analyses indicated that TRACE rats froze significantly more than both PSEUDO $(p<0.01)$ and EXT $(p<0.01)$ rats, whereas PSEUDO rats displayed comparable levels of freezing with EXT rats. During the long-term retention test on day 11, TRACE-RET rats also froze significantly more than EXT-RET rats $(p<0.05)$, suggesting good memory retention for both trace fear conditioning and extinction.

\section{Trace fear conditioning enhances intrinsic excitability of regular spiking IL-BLA projection neurons}

To evaluate the effect of trace fear conditioning on the intrinsic excitability of mPFC-BLA projection neurons, PFC slices were prepared after the memory test, and WCRs were performed on the neurons that were labeled with fluorescent microspheres. Trace fear conditioning significantly increased the intrinsic excitability of regular spiking IL-BLA projection neurons as evidenced by more AP firing in response to depolarizing current steps compared with NAIVE neurons (Fig. $5 A, C$ ). A repeated-measures ANOVA revealed significant main effects of group $\left(F_{(5,103)}=3.0\right.$, $p<0.05)$ and current intensity $\left(F_{(1.6,162.1)}=497.3, p<0.01\right.$; Greenhouse-Geisser corrected). There was also a significant interaction of group by current intensity $\left(F_{(7.9,93.6)}=2.4, p<0.05\right.$; Greenhouse-Geisser corrected). Follow-up analyses using a oneway ANOVA revealed a significant group effect when depolarizing current steps were $>250 \mathrm{pA}$ (all values, $p<0.05$ ). Post hoc comparisons confirmed that cells in TRACE rats fired significantly more APs than those in NAIVE, PSEUDO, EXT, or TRACE-RET rats in response to the depolarizing currents ranging between 250 and $400 \mathrm{pA}$ (Fig. 5A). Interestingly, the intrinsic excitability was not enhanced in TRACE-RET rats, although they displayed good memory retention $10 \mathrm{~d}$ after conditioning, suggesting the conditioninginduced effect was transient, which is consistent with previous studies in hippocampal neurons after trace eyeblink conditioning (Moyer et al., 1996; Thompson et al., 1996) and odor discrimination learning (Zelcer et al., 2006). The enhancement of intrinsic excitability was also not observed in EXT or EXT-RET rats. In both groups, intrinsic excitability was comparable with that of neurons from naive rats (Fig. $5 A, C$ ), suggesting that extinction reversed the effects of trace fear conditioning.

Although PSEUDO rats displayed an increase in trace interval freezing during conditioning, their freezing levels during the probe test were not only similar to rats that underwent extinction but they were also significantly lower than the TRACE rats (Fig. 2B). Not surprisingly, intrinsic excitability in IL-BLA projection neurons from PSEUDO rats was not significantly changed (Fig. $5 \mathrm{~A}, \mathrm{C}$ ), suggesting that the enhancement of intrinsic excitability in trace fear conditioned rats was associative and learning specific. Thus, our results indicate that acquisition of trace fear conditioning transiently enhances the intrinsic excitability of IL-BLA projection neurons and extinction reverses the effect of conditioning.

\section{Trace fear conditioning modulates spike threshold and $h$ current $\left(I_{h}\right)$ in regular spiking IL-BLA projection neurons} To further explore the underlying mechanisms that may contribute to our observed learning-related enhancement of neuronal excitability, basic membrane properties as well as the postburst AHP were also compared between the various training groups. A planned comparison between neurons from naive and conditioned animals suggests that the spike threshold was significantly hyperpolarized after conditioning $\left(t_{(40)}=2.4, p<0.05\right.$; Fig. $6 A$ ) 
A

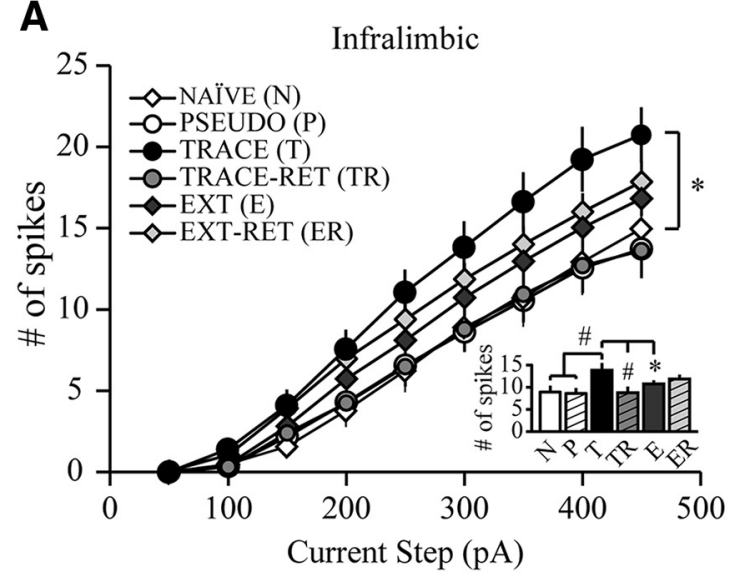

C

Infralimbic
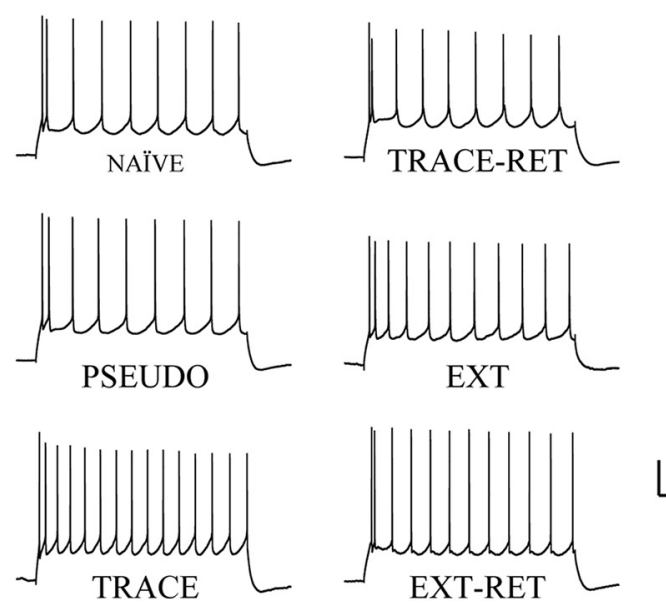

B

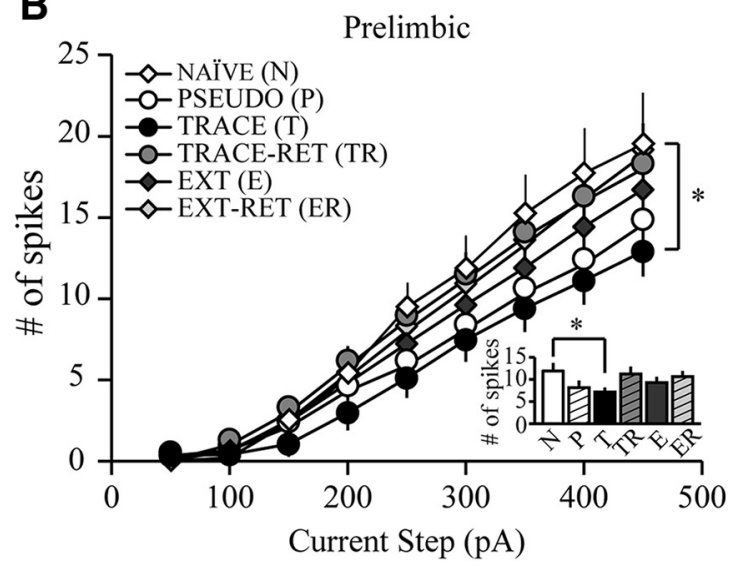

D
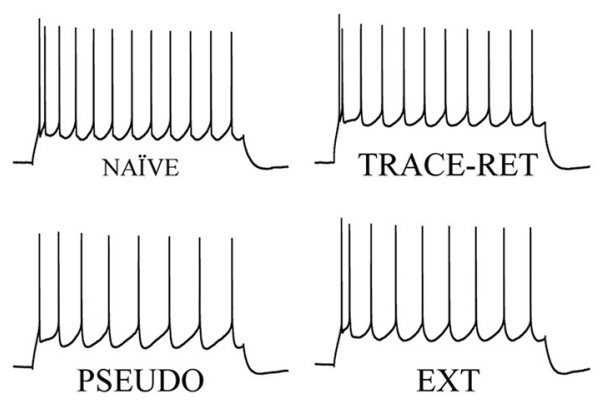

Figure 5. Trace fear conditioning differentially modulates the intrinsic excitability of regular spiking IL- and PL-BLA projection neurons. $\boldsymbol{A}$, Trace fear conditioning significantly enhanced the intrinsic excitability of IL-BLA projection neurons. Neurons from TRACE rats fired significantly more spikes than those from NAIVE rats $(p<0.05)$. B, Trace fear conditioning significantly suppressed the intrinsic excitability of PL-BLA projection neurons. Neurons from TRACE rats fired significantly fewer spikes than those from NAIVE rats $(p<0.05)$. In both IL and PL subregions, extinction reversed the conditioning effect such that the intrinsic excitability in EXT neurons was comparable with neurons from other groups and remained stable after extinction retention (EXT-RET). The conditioning-induced plasticity observed in TRACE rats was transient in both IL and PL subregions as the intrinsic excitability returned to naive level after memory retention (TRACE-RET). The insets in $\boldsymbol{A}$ and $\boldsymbol{B}$ show the number of spikes evoked by a $300 \mathrm{pA}$ current injection in $\mathrm{mPFC}-\mathrm{BLA}$ projection neurons (statistically different between TRACE and other groups: $\left.{ }^{*} p<0.05,{ }^{\#} p<0.01\right)$. $\boldsymbol{C}, \boldsymbol{D}$, Representative traces showing the number of spikes evoked by a 300 pA current injection. Calibration: $20 \mathrm{mV}, 100 \mathrm{~ms}$.

and that there was a significant correlation between spike threshold and the number of spikes evoked by the depolarizing currents $(r=-0.46, p<0.01)$. The spike threshold returned to naive levels in neurons from the TRACE-RET rats after the $10 \mathrm{~d}$ trace memory retention test such that it was significantly different from that of neurons from the TRACE rats $\left(t_{(32)}=2.1, p<0.05\right.$; Figure $6 A$ ). Furthermore, trace fear conditioning significantly increased the depolarizing sag $\left(t_{(38)}=3.4, p<0.01\right.$; Fig. $6 B$, Table 1 ), suggesting the activation of $I_{h}$, which is mediated by hyperpolarization-activated cyclic nucleotide-gated (HCN) channels. In addition, trace fear conditioning enhanced the mAHP (measured at the peak after a burst of $10 \mathrm{APs}$ ) but not sAHP (measured at $1 \mathrm{~s}$ after the burst of APs; Fig. 6C, Table 1), which is consistent with the activation of $I_{\mathrm{h}}$ (Oswald et al., 2009; Kaczorowski, 2011). That activation of $I_{\mathrm{h}}$ contributed to the enhanced mAHP was also supported by the observation that the mAHP was significantly correlated with the sag $(r=-0.38, p<$ 0.05). Other membrane properties (e.g., RMP, input resistance, $I_{\text {threshold }}$ ) were not significantly different (Table 1). Together, these data suggest that trace fear conditioning specifically en- hances intrinsic excitability of IL-BLA projection neurons through modulating the expression or properties of the ion channels that regulate spike threshold and $I_{\mathrm{h}}$.

Trace fear conditioning suppresses intrinsic excitability of regular spiking PL-BLA projection neurons

In contrast to IL neurons, acquisition of trace fear conditioning significantly reduced the intrinsic excitability of RS neurons in the PL subregion (Fig. $5 B, D$ ). A planned repeatedmeasures ANOVA between NAIVE and TRACE neurons revealed a significant main effect of group $\left(F_{(1,22)}=4.6, p<\right.$ $0.05)$ and current intensity $\left(F_{(1.2,26.7)}=70.4, p<0.01\right.$; Greenhouse-Geisser corrected) but no significant group $\times$ current intensity interaction $\left(F_{(1.2,26.7)}=3.4, p=0.07\right.$; GreenhouseGeisser corrected). Additional analysis with a one-way ANOVA revealed that trace fear conditioned rats fired significantly fewer spikes in response to depolarizing current injections between 250 and $400 \mathrm{pA}$ (all values, $p<0.05$ ). However, the intrinsic neuronal excitability returned to naive levels within $7 \mathrm{~d}$ (TRACE-RET rats). Likewise, the effects of condi- 
A

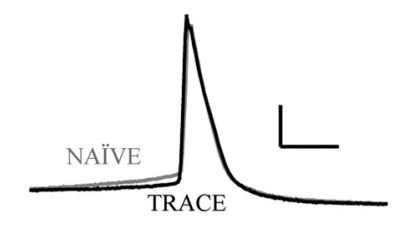

Infralimbic
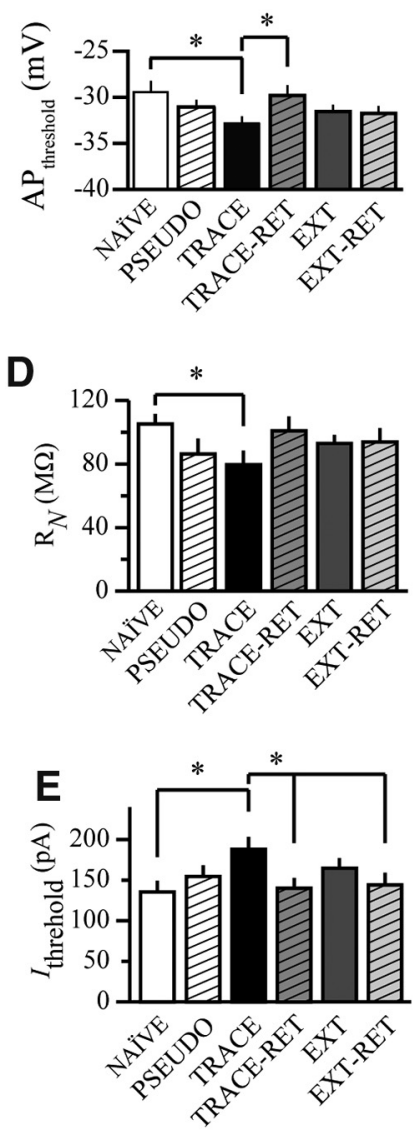

Prelimbic
B
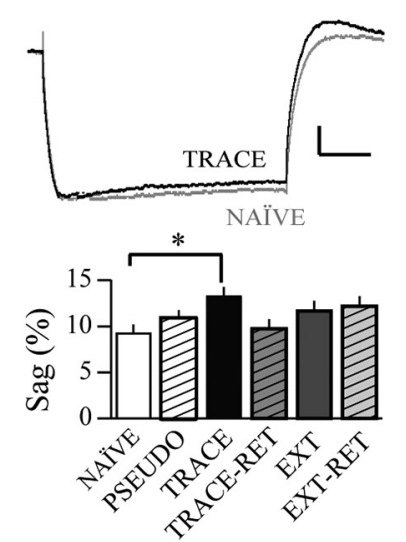

C
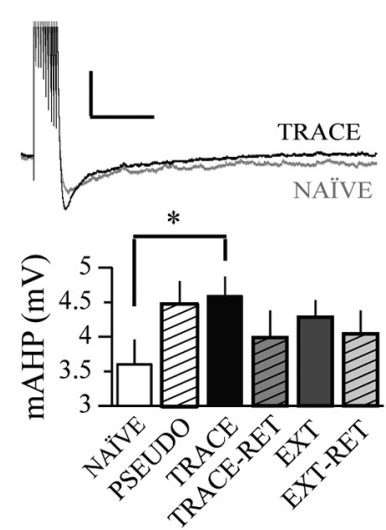

$\mathbf{F}$ $r=-0.79, p<0.01$

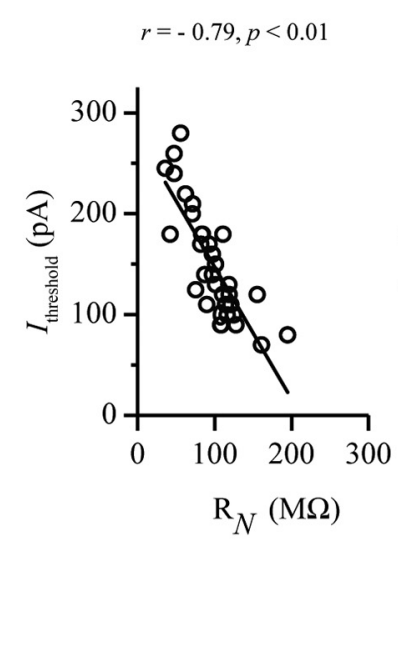

G $r=0.45, p<0.05$

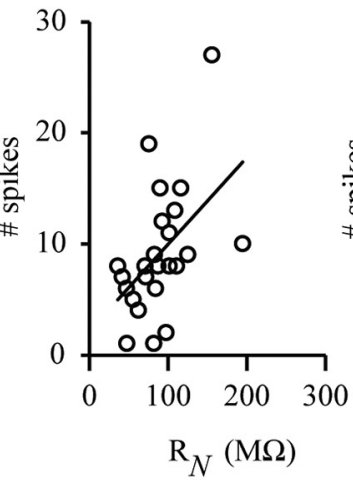

H $r=-0.58, p<0.01$

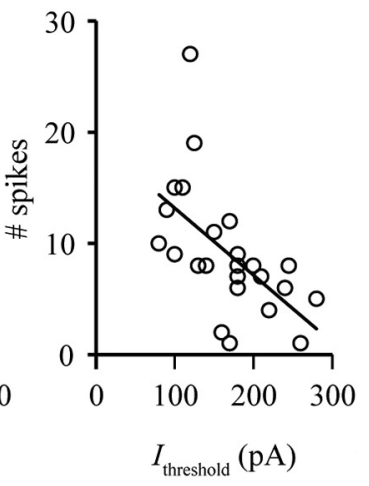

Figure 6. Distinct mechanisms underlie learning-related changes within $\mathrm{mPFC}-\mathrm{BLA}$ projection neurons after acquisition and extinction of trace fear conditioning. $\boldsymbol{A}-\boldsymbol{C}$, In IL subregion, acquisition of trace fear conditioning significantly reduced the AP threshold $(\boldsymbol{A})$, increased the depolarizing sag $(\boldsymbol{B})$, and enhanced the mAHP $(\boldsymbol{C})$. After memory retention (TRACE-RET), the AP threshold returned to naive level and was significantly higher than that of TRACE neurons ( $p<0.05$ ). Calibration: $\boldsymbol{A}, 20 \mathrm{mV}, 2 \mathrm{~ms} ; \boldsymbol{B}, 5 \mathrm{mV}, 100 \mathrm{~ms} ; \boldsymbol{C}, 5 \mathrm{mV}, 0.5 \mathrm{~s}$. $\boldsymbol{D}, \boldsymbol{E}, \mathrm{In} \mathrm{PL}$ subregion, acquisition of trace fear conditioning significantly reduced the neuronal input resistance or $R_{\mathrm{N}}(\boldsymbol{D})$ and increased the minimal current $\left(I_{\text {threshold }}\right)$ required to evoke one action potential or spike $(\boldsymbol{E})$. The $I_{\text {threshold }}$ was reduced to naive level after TRACE-RET or EXT-RET and was significantly different from that of TRACE neurons (for all values, $p<0.05$ ). All other comparisons were not significantly different from $\boldsymbol{A}-\boldsymbol{E}(p>0.05)$. $\boldsymbol{F}-\boldsymbol{H}$, Correlations between $I_{\text {threshold }}$ and $R_{\mathrm{N}}(\boldsymbol{F})$, the number of action potentials and $R_{\mathrm{N}}(\boldsymbol{G})$, and the number of action potentials and $I_{\text {threshold }}(\boldsymbol{H})$ suggest that within PL-BLA projection neurons, the changes in both $R_{\mathrm{N}}$ and $I_{\text {threshold }}$ contribute to the learning-related reduction in intrinsic excitability.

tioning were reversed by extinction (EXT rats), and they remained at naive levels even after a subsequent extinction retention test $7 \mathrm{~d}$ later (e.g., EXT-RET rats), suggesting that extinction permanently reversed the effects of conditioning on intrinsic excitability (Fig. $5 B, D$ ). Thus, the reduction of intrinsic neuronal excitability in PL-BLA projection neurons from trace fear conditioned rats was learning specific, transient, and reversible.

\section{Trace fear conditioning reduces input resistance of regular spiking PL-BLA projection neurons}

Trace fear conditioning induced a subtle but significant reduction in the input resistance $\left(R_{\mathrm{N}}\right)$ of PL-BLA projection neurons $\left(t_{(24)}=2.1, p<0.05\right.$; Fig. $\left.6 D\right)$. Interestingly, this subtle change in $R_{\mathrm{N}}$ was sufficient to significantly reduce the excitability of PLBLA projection neurons such that neurons from the trace fear conditioned rats required a significantly larger threshold current injection $\left(I_{\text {threshold }}\right)$ to evoke a single action potential $\left(t_{(24)}=\right.$ 2.7, $p<0.05$; Figure $6 E$ ). The $I_{\text {threshold }}$ was reduced to naive level after TRACE-RET or EXT-RET and was significantly different from that of TRACE neurons (TRACE-RET: $t_{(26)}=2.2$, $p<0.05$; EXT-RET: $t_{(27)}=2.0, p<0.05$; Fig. $\left.6 E\right)$. The relationship between $R_{\mathrm{N}}$ and $I_{\text {threshold }}$ was supported by the strong correlation between the two measurements $(r=-0.79, p<$ 0.0001 ; Fig. $6 F$ ). Furthermore, the number of spikes evoked by depolarizing current was strongly correlated with both $R_{\mathrm{N}}$ $\left(p<0.05\right.$; Fig. 6G) and $I_{\text {threshold }}(p<0.01$; Fig. $6 H)$. Moreover, the changes in $R_{\mathrm{N}}$ and $I_{\text {threshold }}$ were only observed in conditioned rats but not in pseudoconditioned rats (see also Table 1 for other membrane properties that were not changed by conditioning), suggesting they were learning specific. Thus, trace fear conditioning suppresses the intrinsic excitability of PL-BLA projection neurons by modulating ion channels that affect $R_{\mathrm{N}}$ and $I_{\text {threshold }}$. 
Table 1. Effect of trace fear conditioning and extinction on membrane properties of regular spiking mPFC-BLA projection neurons

\begin{tabular}{|c|c|c|c|c|c|c|c|c|c|}
\hline roup & $\mathrm{MP}(\mathrm{mV})$ & $R_{\mathrm{N}}(\mathrm{M} \Omega)$ & reshold $(\mathrm{pA})$ & $\mathrm{AP}_{\text {thresh }}(\mathrm{mV})$ & $\mathrm{AP}_{\mathrm{amp}}(\mathrm{mV})$ & $\mathrm{AP}_{\text {width }}(\mu \mathrm{s})$ & $\mathrm{mAHP}(\mathrm{mV})$ & sAHP (mV) & Sag (\%) \\
\hline \multicolumn{10}{|c|}{ Infralimbic cortex } \\
\hline NAIVE & $60.7 \pm 1.2(21)$ & $123 \pm 9(21)$ & $147 \pm 12(20)$ & $-29.5 \pm 1.2(20)^{*}$ & $77 \pm 2(20)$ & $971 \pm 49(20)$ & $-4.2 \pm 0.3(20)^{*}$ & $-0.9 \pm 0.1(20)$ & $9.2 \pm 1.0(18$ \\
\hline PS & & 81 & 0 & 18) & 8) & $950 \pm$ & & & 1 \\
\hline TRACE & & $18 \pm 9$ & & & & $968 \pm$ & & & \\
\hline TRACI & $-61.8 \pm 1.2(13)$ & 13) & 12) & -29.8 & & 912 & & & 3) \\
\hline EXT & & 2) & & & & & & & \\
\hline EXT-R & & & & & & & & & \\
\hline \multicolumn{10}{|l|}{ relim } \\
\hline NAIVF & 2) & $105=$ & )$^{*}$ & 2) & & & 12) & 12) & \\
\hline DO & $-62.0 \pm 1.3(9)$ & & & & & & & & \\
\hline TRACE & $-63.4 \pm 0.9(14)$ & $80 \pm 11(14)$ & $88 \pm$ & -32.2 & 2 (14) & $846=$ & $-4.8 \pm 0.3(14)$ & $-0.9=$ & $12.4 \pm 1.1(14)$ \\
\hline TRACE-RET & $-63.0 \pm 1.5(15)$ & $101 \pm 9(15)$ & $140 \pm 13(14)^{*}$ & $-31.5 \pm 0.9(14)$ & $80 \pm 2(14)$ & $750 \pm 26(14)$ & $-4.9 \pm 0.3(15)$ & $-1.0 \pm 0.1(13)$ & $9.4 \pm 1.0(13)$ \\
\hline EXT & $-61.3 \pm 1.2(22)$ & 02 & $165 \pm$ & $-31.3=$ & $82 \pm 2(22)$ & $829 \pm 26(22)$ & $-4.6 \pm 0.3(22)$ & $-0.6 \pm 0.1(22)$ & $11.8 \pm 1.0(22)$ \\
\hline EXT-RET & $-62.8 \pm 1.5(15)$ & $94 \pm 9(15)$ & $144 \pm 15(15)$ & $-33.5 \pm 0.9(15)$ & $85 \pm 2(15)$ & $798 \pm 31(15)$ & $-4.7 \pm 0.4(13)$ & $-0.8 \pm 0.1(13)$ & $11.4 \pm 1.4(13)$ \\
\hline
\end{tabular}

Data are mean \pm SE for the number of cells in parentheses. Rat groups are as follows: NAIVE, rats that did not receive any behavioral training; PSEUD0, rats that received pseudoconditioning on day 1 and tested on day 4; TRACE, rats that received trace fear conditioning on day 1 and tested on day 4; TRACE-RET, rats that received trace fear conditioning on day 1 and tested on day 11; EXT, rats that received trace fear conditioning on day 1, extinction on days $2-3$, and tested on day 4; EXT-RET, rats that received conditioning on day 1, extinction on days $2-3$, and tested on day 11 . AP ${ }_{\text {amp }}$ was relative to threshold. The mAHP was measured at the peak of the AHP within $150 \mathrm{~ms}$ after a burst of 10 APs. The sAHP was measured at $1 \mathrm{~s}$ after the burst of 10 APs. ${ }^{*} p<0.05$, statistically different from TRACE.

\section{Correlations between behavioral performance and intrinsic excitability after conditioning and extinction}

Previous data demonstrated that the amount of conditioned fear was significantly correlated with the intrinsic excitability of hippocampal CA1 neurons in trace fear conditioned but not pseudoconditioned rats (Song et al., 2012). We therefore examined whether such correlations also exist in $\mathrm{mPFC}$ neurons after trace fear conditioning and extinction. Data from IL-BLA projection neurons revealed a significant positive correlation between behavioral performance (percentage freezing) and intrinsic excitability in the TRACE rats (Fig. 7A). In contrast, data from PL-BLA projection neurons revealed a significant negative correlation between behavioral performance and intrinsic excitability in the EXT rats (Fig. 7B). No other significant correlations were observed within IL or PL subregions. Thus, these data suggest that the activity of regular spiking IL-BLA projection neurons is critical for the formation of the trace conditioned fear memory, whereas the activity of regular spiking PL-BLA projection neurons is critical for extinction of this memory.

\section{Trace fear conditioning enhances the intrinsic excitability of burst spiking PL-BLA projection neurons}

Neurons that generated two or more action potentials in an all-or-none fashion in response to a just-suprathreshold current injection $\left(I_{\text {threshold }}\right)$ were classified as BS neurons (Connors et al., 1982; Moyer et al., 2002). BS and RS neurons display different firing patterns, which may be related to differences in the distribution and/or properties of their voltagegated (especially $\mathrm{T}$ - and $\mathrm{R}$-type $\mathrm{Ca}^{2+}$ ) ion channels (Magee and Carruth, 1999). Our previous data demonstrated that enhanced intrinsic excitability in L2/3 BS neurons may underlie aging-related extinction deficits (Kaczorowski et al., 2012), suggesting that bursting activity enhances conditioned fear. We therefore analyzed BS neurons separately. A total of 30 burst spiking mPFC-BLA projection neurons (9 IL-BLA, 21 PL-BLA) were obtained in this study (Fig. 4B, Table 2). These represent 7 and $19 \%$ of the total number of IL- and PL-BLA projection neurons, respectively. Within the IL subregion, no BS neurons were obtained from NAIVE or PSEUDO rats. Interestingly, there seems to be an increase in the percentage of BS neurons after behavioral training, especially after extinction (percentage BS neurons in the IL subregion: TRACE, 8\%;
TRACE-RET, 7\%; EXT, 15\%; EXT-RET, 8\%). No further statistics were performed in IL burst spiking neurons because of the small sample size. Interestingly, this observed trend toward an increase in bursting activity after extinction of trace fear conditioning is consistent with previous findings in IL neurons after extinction of delay fear conditioning (Santini et al., 2008).

Within the PL subregion, the intrinsic excitability of BS neurons was significantly enhanced after trace fear conditioning (Fig. 8, Table 2). Since bursting may be an important way for the brain to synchronize activity between brain regions (Buzsáki et al., 2002), this enhanced bursting activity within PL-BLA projection neurons may be critical for the expression of a trace fear memory. Interestingly, this change was opposite to that observed in regular spiking PL-BLA projection neurons, in which intrinsic excitability was reduced after conditioning (Fig. 9A). Moreover, other membrane properties, such as $R_{\mathrm{N}}$ and $I_{\text {threshold }}$, were also changed in burst spiking PL-BLA projection neurons after trace fear condoning, but opposite to those observed in regular spiking PL-BLA projection neurons (Fig. 9B,C). Together, these data suggest that trace fear conditioning differently modulates the intrinsic excitability of regular spiking and bust spiking PL-BLA projection neurons.

\section{Discussion}

With the combination of retrograde labeling and whole-cell patch-clamp recordings, we demonstrate for the first time that trace fear conditioning significantly alters the intrinsic excitability of $\mathrm{MPFC}-\mathrm{BLA}$ projection neurons in a subregion- and cell-type-specific manner. Interestingly, the conditioninginduced effects were reversed by extinction as well as the passage of time, since they were not evident during the memory retention test given $10 \mathrm{~d}$ after conditioning. Thus, these data suggest that the intrinsic plasticity within $\mathrm{mPFC}-\mathrm{BLA}$ projection neurons is required for the consolidation of, but not for the retrieval of, a trace fear memory.

\section{Learning-induced intrinsic plasticity within MPFC-BLA projection neurons supports memory consolidation}

In both IL and PL subregions, we observed transient changes in intrinsic excitability, which were diminished over time (e.g., TRACE-RET group) or with extinction. These data suggest that the conditioning-induced intrinsic plasticity was re- 
A
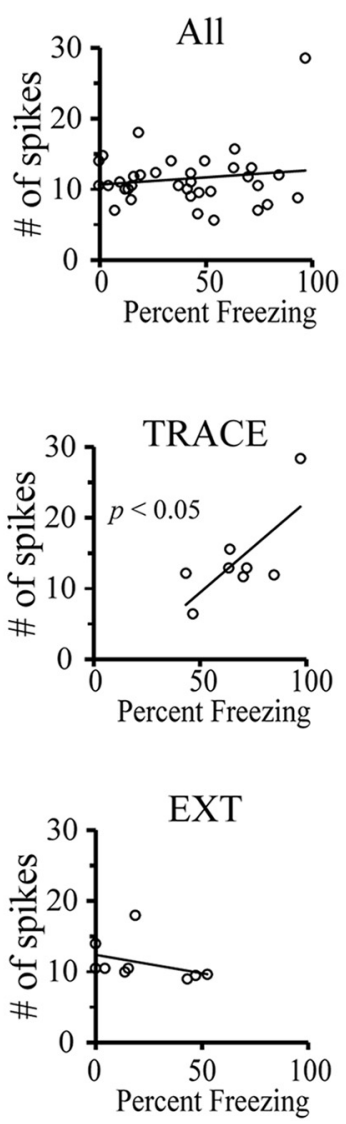
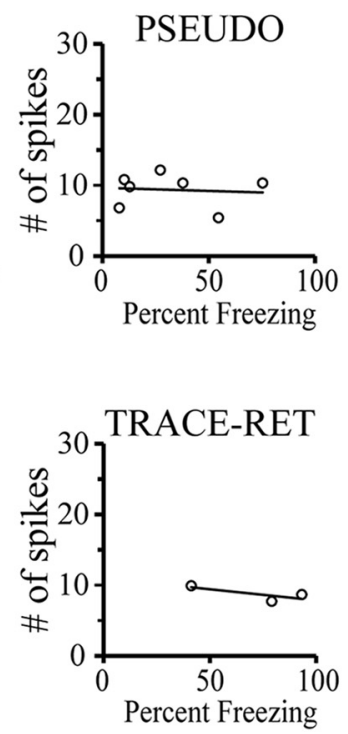

Infralimbic

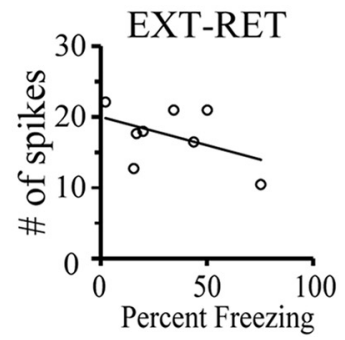

B
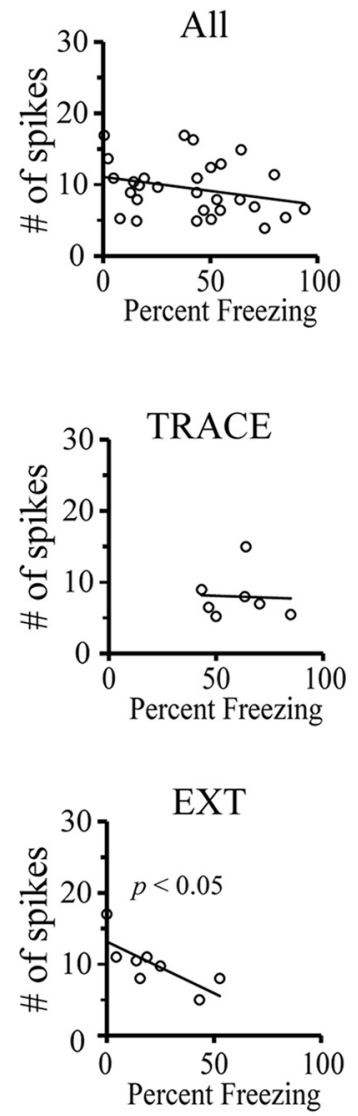
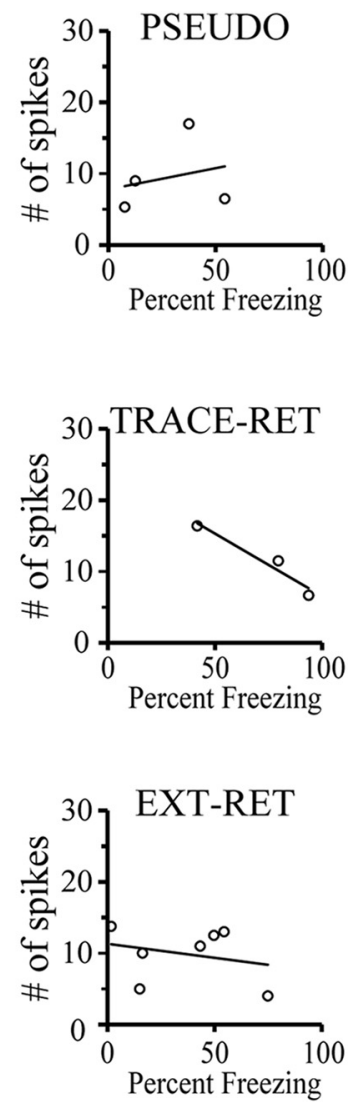

Figure 7. Acquisition and extinction of trace fear conditioning are differentially correlated with intrinsic excitability of regular spiking mPFC-BLA projection neurons. A, Within the IL subregion, a significant correlation was observed in neurons from TRACE rats $(r=0.73, p<0.05)$ but not in any other groups or when all groups were combined together ( $p$ values for other groups were as follows: All, 0.40; PSEUD0, 0.84; TRACE-RET, 0.45; EXT, 0.33; EXT-RET, 0.25). B. Within the PL subregion, a significant correlation was observed in neurons from rats that received extinction (EXT; $r=$ $-0.72, p<0.05$ ) but not any other groups ( $p$ values for other groups were as follows: All, 0.15; PSEUD0, 0.75 TRACE, 0.92; TRACE-RET, 0.16; EXT-RET, 0.57).

Table 2. Effect of trace fear conditioning and extinction on membrane properties of burst-spiking mPFC-BLA projection neurons

\begin{tabular}{|c|c|c|c|c|c|c|c|c|c|}
\hline Group & $\operatorname{RMP}(\mathrm{mV})$ & $R_{\mathrm{N}}(\mathrm{M} \Omega)$ & $I_{\text {threshold }}(\mathrm{pA})$ & $\mathrm{AP}_{\text {thresh }}(\mathrm{mV})$ & $\mathrm{AP}_{\mathrm{amp}}(\mathrm{mV})$ & $\mathrm{AP}_{\text {width }}$ (ms) & Number of spikes & $\mathrm{mAHP}(\mathrm{mV})$ & Sag (\%) \\
\hline \multicolumn{10}{|c|}{$\begin{array}{l}\text { Infralimbic cortex } \\
\text { NAIVE } \\
\text { PSEUDO }\end{array}$} \\
\hline TRACE & $-59.0 \pm 3(2)$ & $84.7 \pm 7(2)$ & $160 \pm 40(2)$ & $-31.7 \pm 5.4(2)$ & $88 \pm 4(2)$ & $0.66 \pm 0.04(2)$ & $8(1)$ & $-4.9(1)$ & $12.4 \pm 8.3$ \\
\hline TRACE-RET & $-62.0(1)$ & 79.7 (1) & $180(1)$ & $-35.2(1)$ & $95(1)$ & $0.60(1)$ & $12(1)$ & $-4.3(1)$ & $5.4(1)$ \\
\hline EXT & $-66.3 \pm 1.4(4)$ & $97 \pm 15(4)$ & $133 \pm 13(4)$ & $-34.2 \pm 4(4)$ & $92 \pm 9(4)$ & $0.72 \pm 0.07(4)$ & $17 \pm 4(4)$ & $-2.9 \pm 0.4(4)$ & $3.5 \pm 0.7(4)$ \\
\hline EXT-RET & $-59.5 \pm 5.5(2)$ & $74 \pm 33(2)$ & $170 \pm 90(2)$ & $-39.1 \pm 0.9(2)$ & $91 \pm 3(2)$ & $0.73 \pm 0.02(2)$ & $15 \pm 9(2)$ & $-5.3 \pm 1.7(2)$ & $16.1 \pm 0.3(2)$ \\
\hline \multicolumn{10}{|l|}{ Prelimbic cortex } \\
\hline NAIVE & $-66.0 \pm 2.1(5)$ & $110 \pm 4(5)$ & $116 \pm 6(5)$ & $-35 \pm 1.7(5)$ & $90 \pm 3(5)$ & $0.66 \pm 0.05(5)$ & $12 \pm 3(5)^{*}$ & $-4.5 \pm 0.8(5)$ & $8.2 \pm 2.6(4)$ \\
\hline PSEUDO & $-63.0(1)$ & $101(1)$ & $120(1)$ & $-34.4(1)$ & $90(1)$ & $0.86(1)$ & $14(1)$ & $-5.0(1)$ & $9.7(1)$ \\
\hline TRACE & $-66.0 \pm 1.2(3)$ & $132 \pm 16(3)$ & $87 \pm 9(3)$ & $-34.6 \pm 0.3(3)$ & $93 \pm 2(3)$ & $0.68 \pm 0.04(3)$ & $21 \pm 1(3)$ & $-5.4 \pm 0.5(3)$ & $8.0 \pm 1.4(3)$ \\
\hline TRACE-RET & $-64.0 \pm 0.9(4)$ & $85 \pm 8(4)$ & $130 \pm 20(4)$ & $-31.6 \pm 0.9(4)$ & $80 \pm 1(4)$ & $0.78 \pm 0.02(4)$ & $12 \pm 2(4)$ & $-5.4 \pm 0.8(4)$ & $7.8 \pm 1.3(4)$ \\
\hline EXT & $-60.3 \pm 1.8(3)$ & $110 \pm 106(3)$ & $113 \pm 23(3)$ & $-32.9 \pm 1.4(3)$ & $93 \pm 2(3)$ & $0.60 \pm 0.01(3)$ & $16 \pm 4(3)$ & $-4.8 \pm 0.4(3)$ & $9.4 \pm 0.3(3)$ \\
\hline EXT-RET & $-66.0 \pm 1.2(5)$ & $112 \pm 10(5)$ & $112 \pm 13(5)$ & $-32.5 \pm 2.1(5)$ & $89 \pm 6(5)$ & $0.70 \pm 0.11(5)$ & $16 \pm 3(5)$ & $-4.3 \pm 0.3(5)$ & $5.3 \pm 1.0(5)$ \\
\hline
\end{tabular}

Data are mean \pm SE for the number of cells in parentheses. Rat groups are as follows: NAIVE, rats that did not receive any behavioral training; PSEUDO, rats that received pseudoconditioning on day 1 and tested on day 4; TRACE, rats that received trace fear conditioning on day 1 and tested on day 4; TRACE-RET, rats that received trace fear conditioning on day 1 and tested on day 11; EXT, rats that received trace fear conditioning on day 1, extinction on days $2-3$, and tested on day 4; EXT-RET, rats that received conditioning on day 1, extinction on days $2-3$, and tested on day 11 . AP amp was relative to threshold. The mAHP was measured at the peak of the AHP within 150 ms after a burst of 10 APs. The number of spikes was counted from a voltage response to a 300 pA depolarizing current injection. ${ }^{*} p<0.05$, statistically different from TRACE.

lated to more of a systems-level consolidation (rather than a rapid synaptic consolidation) involving a gradual reorganization of the brain regions that support the memory (Frankland and Bontempi, 2005). Such transient changes have been observed in hippocampal neurons after trace eyeblink conditioning (Moyer et al., 1996; Thompson et al., 1996) as well as olfactory discrimination rule learning (Zelcer et al., 2006). In addition to memory consolidation, this learning-induced intrinsic plasticity may also facilitate synaptic plasticity and subsequent learning (i.e., metaplasticity; see Abraham and Bear, 1996; Zelcer et al., 2006; and Sehgal et al., 2013). It is likely that the learning-induced intrinsic plasticity creates a hyperexcit- 

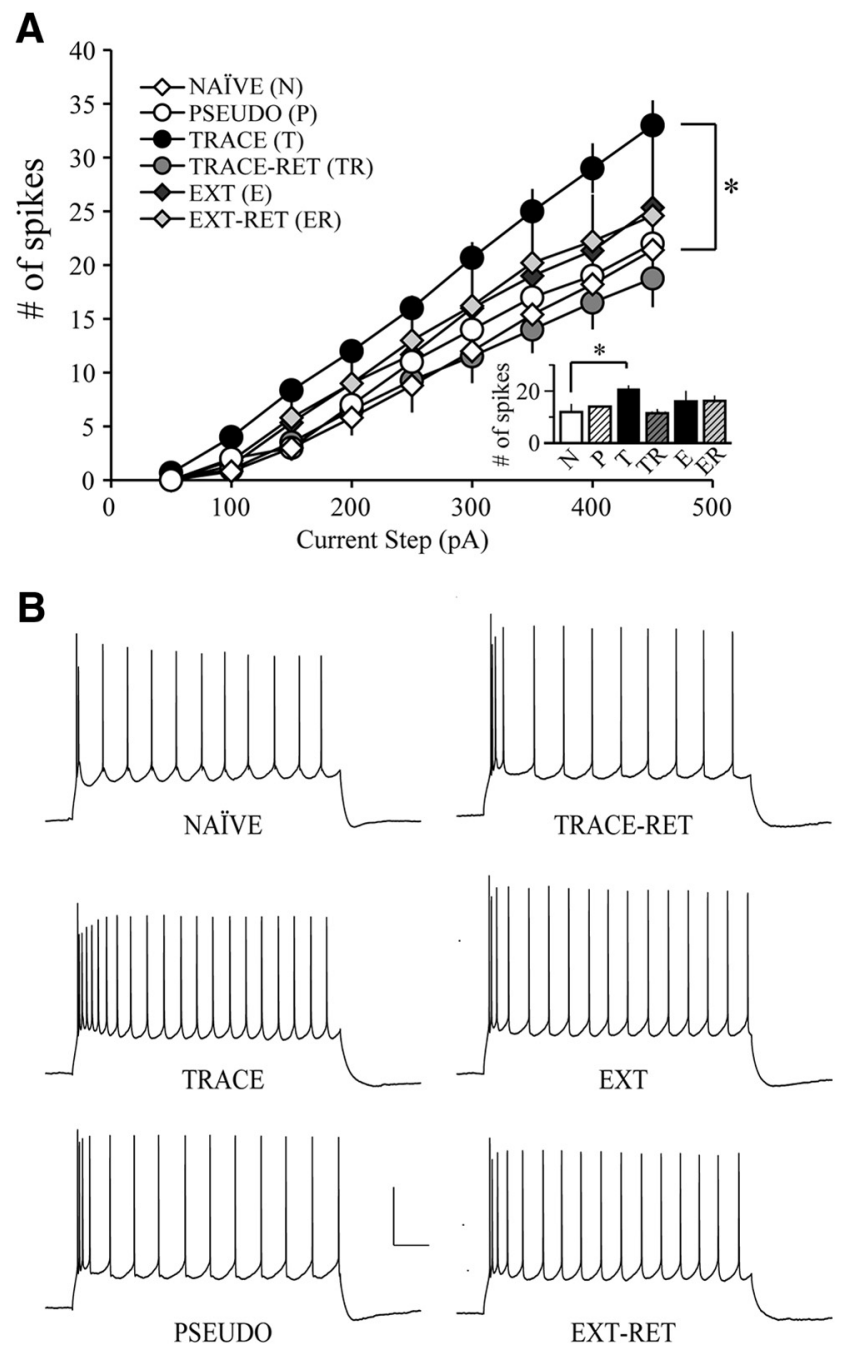

Figure 8. Trace fear conditioning enhances intrinsic excitability of burst spiking PL-BLA projection neurons. $A$, Trace fear conditioning significantly enhanced the intrinsic excitability of burst spiking PL-BLA projection neurons $\left(F_{(1,6)}=6.1, p<0.05\right.$; planned repeated-measures ANOVA). Student's $t$ test confirmed that cells in TRACE rats fired significantly more APs than those in NAIVE rats in response to the depolarizing currents ranging between 100 and $300 \mathrm{pA}$ (for all values, $p<0.05$ ). Inset, Bar graph showing the average number of spikes evoked by 300 $\mathrm{pA}$ depolarizing currents from all groups. The asterisk indicates statistically significant difference between neurons from NAIVE and TRACE rats $\left(F_{(1,6)}=7.6, p<0.05\right.$; planned comparison). $\boldsymbol{B}$, Representative voltage traces illustrating that PL-BLA projection neurons from trace conditioned rats fired more action potentials than neurons from naive rats (calibration: $40 \mathrm{mV}$, $100 \mathrm{~ms})$.

able or hypoexcitable state to promote memory consolidation (Zhang and Linden, 2003). Furthermore, the transient feature of learning-induced plasticity also suggests that some regulatory process exists for restoring excitability. Although our data suggest that intrinsic plasticity within $\mathrm{MPFC}$ is not required for expression of the trace fear memory $10 \mathrm{~d}$ later (Figs. 2, 5), pharmacological inactivation of mPFC severely impairs the expression of conditioned fear (Blum et al., 2006; Corcoran and Quirk, 2007), suggesting that another process, such as synaptic plasticity (Song et al., 2012), may exist during longterm memory retrieval.

\section{Learning-induced intrinsic plasticity in $\mathrm{MPFC}$ is subregion} and cell-type specific

Trace fear conditioning significantly enhanced the intrinsic excitability of regular spiking IL-BLA projection neurons (Fig.
$5 A$ ). As illustrated in Table 3, $10 \%$ of the neurons were defined as "changed." Our observation that learning alters the excitability of only a subset of neurons is consistent with prior studies (Moyer et al., 1996; Rumpel et al., 2005; Sehgal et al., 2014) and suggests that not every labeled IL-BLA projection neuron underwent trace fear conditioning-associated changes. In contrast, the excitability of regular spiking PLBLA projection neurons was suppressed (Fig. $5 B$ ), with $\sim 14 \%$ of labeled neurons exhibiting a decreased excitability after trace fear conditioning.

Our results suggest that the activity of IL-BLA projection neurons enhances fear memory consolidation (Figs. 5A, 7A), whereas the activity of PL-BLA projection neurons inhibits the expression of conditioned fear (Figs. 5B, 7B). This is consistent with other studies showing that local blockade of NMDARs in the IL subregion decreased both delay and trace conditioned fear (Kwapis et al., 2014b), whereas PL lesions or local blockade of PL NMDARs increased both delay (Morgan and LeDoux, 1995) and trace conditioned fear (Kwapis et al., 2014b). Similarly, our recent data suggest that the intrinsic excitability of IL neurons is enhanced $24 \mathrm{~h}$ after delay fear conditioning in adult rats (Song et al., 2015). Previous studies also suggested that delay fear conditioning suppressed the firing activity of PL neurons during the CS test (Garcia et al., 1999). Such suppression may arise from the activation of BLA and IL during memory recall because stimulation of either brain region inhibited PL neuronal activity (Pérez-Jaranayand Vives, 1991; Ji and Neugebauer, 2012; Dilgen et al., 2013). After extinction, such inhibition was reversed and even converted into potentiation (Herry et al., 1999; Herry and Garcia, 2002), thus allowing PL neurons to inhibit fear. Conversely, synaptic strength within the IL-BLA pathway is enhanced after delay fear conditioning and reversed by extinction (Vouimba and Maroun, 2011). Together, these data suggest that our observations are general for fear conditioning and that IL and PL subregions are involved in consolidation and extinction of conditioned fear, but that their roles are opposing.

Although our observations are consistent with other studies, some discrepancies exist (for review, see Kim and Jung, 2006). For instance, Porter and colleagues (Santini et al., 2008) showed that intrinsic excitability of IL neurons was suppressed, whereas the excitability of PL neurons did not change after delay fear conditioning. There are several possible explanations for these discrepancies. First, Porter and colleagues (Santini et al., 2008) recorded from mPFC pyramidal neurons within both $\mathrm{L} 2 / 3$ and L5, whereas the present study recorded from only L5 mPFC-BLA projection neurons. Second, recent studies suggest that the brain circuits underlying acquisition and extinction of delay and trace fear paradigms are different. Although extinction of delay requires the amygdala (Falls et al., 1992; Parsons et al., 2010) and the IL subregion (Burgos-Robles et al., 2007; Sotres-Bayon et al., 2009; Pattwell et al., 2012), extinction of trace fear conditioning does not require the amygdala, but it does require IL, PL, and retrosplenial cortices (Kwapis et al., 2014a,b). Our observation that IL excitability correlates with behavioral performance after conditioning whereas PL excitability correlates with behavioral performance after extinction is consistent with Kwapis et al. (2014b). However, our data do not rule out transient changes to IL excitability that may occur during extinction training after either delay or trace conditioning. Finally, a number of other procedural differences (e.g., animal age, recording temperature, external and internal recording solutions) may account for the 
discrepancies between the current study and that of Santini et al. (2008).

We observed that both RS and BS projection neurons are involved in fear memory consolidation. Although the role of $\mathrm{BS}$ neurons is obscured by the small sample size compared with that of RS neurons, this effect was robust and consistent with previous studies showing that stimulation of BLA inhibits most mPFC pyramidal neurons (PérezJaranayand Vives, 1991; Dilgen et al., 2013) and excites most mPFC interneurons (Dilgen et al., 2013). These observations are also reminiscent of intrinsic plasticity observed in mPFC after olfactory fear conditioning, which excites those neurons that receive monosynaptic inputs from BLA (Laviolette et al., 2005) as well as those neurons that project to the nucleus accumbens, but not those that project to the contralateral mPFC (McGinty and Grace, 2008). Thus, it is likely that learning-induced intrinsic plasticity is specific to $\mathrm{mPFC}-\mathrm{BLA}$ projection neurons but not all mPFC neurons, or even all mPFC-BLA projection neurons (Table 3).

\section{Distinct mechanisms underlie trace fear conditioning- induced intrinsic plasticity in IL and PL subregions}

In IL-BLA projection neurons, the enhanced intrinsic excitability of RS neurons was associated with a reduction in AP threshold (Fig. 6A) and an enhancement in $I_{\mathrm{h}}$ (Fig. 6 $B, C$ ). One possible explanation for our observed reduction in spike threshold is an activity-dependent increase in the probability of opening of somatic voltage-gated sodium channels, which has been previously observed in hippocampal neurons (Ganguly et al., 2000; Xu et al., 2005). It is likely that our observed enhancement in $I_{\mathrm{h}}$ as well as the mAHP in infralimbic RS neurons is mediated by $\mathrm{HCN}$ channels because the selective HCN channel blocker ZD7288 diminishes both components (Kaczorowski, 2011; Angelo and Margrie, 2011). A learningspecific, temporary enhancement of $I_{\mathrm{h}}$ was also observed in hippocampal CA1 neurons after trace eyeblink conditioning (Moyer et al., 1996), suggesting that modulation of HCN channels may play a role in brain regions involved in acquisition of trace paradigms. Interestingly, such learning-specific modulation of $I_{\mathrm{h}}$ was not observed in hippocampal or mPFC neurons after delay eyeblink or fear conditioning (Disterhoft et al., 1986; Santini et al., 2008). Although it remains unclear how $I_{\mathrm{h}}$ uniquely contributes to different learning paradigms, it may facilitate cortical rhythmic oscillations during slow-wave sleep and potentiate memory consolidation (McCormick and Pape, 1990; Lüthi and McCormick, 1998; Marshall et al., 2006).

Within PL-BLA projection neurons, the effects of trace fear conditioning on input resistance was cell-type specific $\left(R_{\mathrm{N}}\right.$ was decreased in RS neurons and increased in BS neurons). The activity-dependent modulation of $R_{\mathrm{N}}$ has been observed not only in cerebellar granule cells after high-frequency stimulation of mossy fiber inputs (Armano et al., 2000) but also in amygdala neurons after fear conditioning (Rosenkranz and Grace, 2002). In both cases, the increase in $R_{\mathrm{N}}$ significantly enhanced intrinsic excitability. Within PL-BLA regular spiking projection neurons, however, there was a significant neg-

$\begin{aligned} & \text { Table 3. Trace fear conditioning alters intrinsic excitability in a subset of IL-BLA } \\
& \text { projection neurons }\end{aligned}$
\begin{tabular}{lcl}
\hline Group & Number of spikes & Ratio of cells changed \\
\hline NAIVE & $9.0 \pm 1.3$ & $0: 15$ \\
PSEUDO & $8.6 \pm 1.2$ & $0: 18$ \\
TRACE & $13.9 \pm 1.6^{*, * *}$ & $2: 20$ \\
TRACE-RET & $8.8 \pm 1.4$ & $0: 13$ \\
EXT & $10.7 \pm 0.9$ & $0: 22$ \\
EXT-RET & $11.9 \pm 1.0$ & $1: 21$
\end{tabular}

Data are the number of action potentials elicited in response to a $300 \mathrm{pA}$ current injection for $1 \mathrm{~s}$. The ratio of cells changed refers to the number of individual neurons (relative to the total number of neurons recorded) whose action potential output at $300 \mathrm{pA}$ was more than 2 SDs beyond the mean of neurons from NAIVE rats. Data from the TRACE group are significantly different from the NAIVE, PSEUDO, TRACE-RET ( $\left.{ }^{*} p<0.01\right)$, and EXT $(* * p<0.05)$ groups.

ative correlation between $I_{\text {threshold }}$ and $R_{\mathrm{N}}$, suggesting that as neuronal input resistance decreased, a concomitant increase in the current required to elicit an action potential was observed (Fig. 6F). These changes, in turn, led to a decrease in the intrinsic excitability of PL regular spiking neurons after trace fear conditioning. This was also supported by (1) a significant positive correlation between intrinsic excitability and $R_{\mathrm{N}}$ (Fig. 6G) and (2) a significant negative correlation between intrinsic excitability and $I_{\text {threshold }}$ (Fig. $6 H$ ).

\section{Conclusions}

The current data are the first to demonstrate that trace fear conditioning modulates the intrinsic excitability of layer 5 $\mathrm{mPFC}-\mathrm{BLA}$ projection neurons in a subregion- and cell-typespecific manner. The intrinsic excitability of regular spiking IL-BLA projection neurons was enhanced after acquisition of trace fear conditioning in a learning-specific manner, suggesting that these neurons are involved in the formation of longterm conditioned fear memory. In contrast, the intrinsic excitability of regular spiking PL-BLA projection neurons was reduced after conditioning and was negatively correlated with the amount of conditioned fear after extinction, suggesting that these neurons are involved in the suppression of conditioned fear. Interestingly, the excitability of burst spiking PLBLA projection neurons was enhanced after conditioning, which was opposite to that observed in regular PL-BLA projection neurons. Together, these data provide new information about how intrinsic changes within IL- and PL-BLA projection neurons are differentially involved in the formation and regulation of a trace fear conditioned memory. 


\section{References}

Abraham WC, Bear MF (1996) Metaplasticity: the plasticity of synaptic plasticity. Trends Neurosci 19:126-130. CrossRef Medline

Angelo K, Margrie TW (2011) Population diversity and function of hyperpolarization-activated current in olfactory bulb mitral cells. Sci Rep 1:50. CrossRef Medline

Armano S, Rossi P, Taglietti V, D’Angelo E (2000) Long-term potentiation of intrinsic excitability at the mossy fiber-granule cell synapse of rat cerebellum. J Neurosci 20:5208-5216. Medline

Blanchard RJ, Blanchard DC (1969) Crouching as an index of fear. J Comp Physiol Psychol 67:370-375. CrossRef Medline

Blum S, Hebert AE, Dash PK (2006) A role for the prefrontal cortex in recall of recent and remote memories. Neuroreport 17:341-344. CrossRef Medline

Boudewijns ZS, Groen MR, Lodder B, McMaster MT, Kalogreades L, de Haan R, Narayanan RT, Meredith RM, Mansvelder HD, de Kock CP (2013) Layer-specific high-frequency action potential spiking in the prefrontal cortex of awake rats. Front Cell Neurosci 7:99. CrossRef Medline

Burgos-Robles A, Vidal-Gonzalez I, Santini E, Quirk GJ (2007) Consolidation of fear extinction requires NMDA receptor-dependent bursting in the ventromedial prefrontal cortex. Neuron 53:871-880. CrossRef Medline

Buzsáki G, Csicsvari J, Dragoi G, Harris K, Henze D, Hirase H (2002) Homeostatic maintenance of neuronal excitability by burst discharges in vivo. Cereb Cortex 12:893-899. CrossRef Medline

Clark RE, Squire LR (1998) Classical conditioning and brain systems: the role of awareness. Science 280:77-81. CrossRef Medline

Connors BW, Gutnick MJ, Prince DA (1982) Electrophysiological properties of neocortical neurons in vitro. J Neurophysiol 48:1302-1320. Medline

Corcoran KA, Quirk GJ (2007) Activity in prelimbic cortex is necessary for the expression of learned, but not innate, fears. J Neurosci 27:840-844. CrossRef Medline

DeFelipe J, Fariñas I (1992) The pyramidal neuron of the cerebral cortex: morphological and chemical characteristics of the synaptic inputs. Prog Neurobiol 39:563-607. CrossRef Medline

Dembrow NC, Chitwood RA, Johnston D (2010) Projection-specific neuromodulation of medial prefrontal cortex neurons. J Neurosci 30:1692216937. CrossRef Medline

Detert JA, Kampa ND, Moyer JR Jr (2008) Differential effects of training intertrial interval on acquisition of trace and long-delay fear conditioning in rats. Behav Neurosci 122:1318-1327. CrossRef Medline

Dilgen J, Tejeda HA, O’Donnell P (2013) Amygdala inputs drive feedforward inhibition in the medial prefrontal cortex. J Neurophysiol 110:221229. CrossRef Medline

Disterhoft JF, Coulter DA, Alkon DL (1986) Conditioning-specific membrane changes of rabbit hippocampal neurons measured in vitro. Proc Natl Acad Sci U S A 83:2733-2737. CrossRef Medline

Falls WA, Miserendino MJ, Davis M (1992) Extinction of fear-potentiated startle: blockade by infusion of an NMDA antagonist into the amygdala. J Neurosci 12:854-863. Medline

Frankland PW, Bontempi B (2005) The organization of recent and remote memories. Nat Rev Neurosci 6:119-130. CrossRef Medline

Gabbott PL, Bacon SJ (1996) Local circuit neurons in the medial prefrontal cortex (areas 24a,b,c, 25 and 32) in the monkey: II. Quantitative areal and laminar distributions. J Comp Neurol 364:609-636. CrossRef Medline

Gabbott PL, Warner TA, Jays PR, Salway P, Busby SJ (2005) Prefrontal cortex in the rat: projections to subcortical autonomic, motor, and limbic centers. J Comp Neurol 492:145-177. CrossRef Medline

Gaillard F, Sauve Y (1995) Fetal tissue allografts in the central visual system of rodents. In: Webvision: the organization of the retina and visual system (Kolb H, Fernandez E, Nelson R, eds). Salt Lake City: University of Utah Health Sciences Center.

Ganguly K, Kiss L, Poo M (2000) Enhancement of presynaptic neuronal excitability by correlated presynaptic and postsynaptic spiking. Nat Neurosci 3:1018-1026. CrossRef Medline

Garcia R, Vouimba RM, Baudry M, Thompson RF (1999) The amygdala modulates prefrontal cortex activity relative to conditioned fear. Nature 402:294-296. CrossRef Medline

Gilmartin MR, Helmstetter FJ (2010) Trace and contextual fear conditioning require neural activity and NMDA receptor-dependent transmission in the medial prefrontal cortex. Learn Mem 17:289-296. CrossRef Medline

Gilmartin MR, Miyawaki H, Helmstetter FJ, Diba K (2013) Prefrontal activity links nonoverlapping events in memory. J Neurosci 33:1091010914. CrossRef Medline

Groh A, Meyer HS, Schmidt EF, Heintz N, Sakmann B, Krieger P (2010) Cell-type specific properties of pyramidal neurons in neocortex underlying a layout that is modifiable depending on the cortical area. Cereb Cortex 20:826-836. CrossRef Medline

Han CJ, O'Tuathaigh CM, van Trigt L, Quinn JJ, Fanselow MS, Mongeau R, Koch C, Anderson DJ (2003) Trace but not delay fear conditioning requires attention and the anterior cingulate cortex. Proc Natl Acad Sci U S A 100:13087-13092. CrossRef Medline

Hattox AM, Nelson SB (2007) Layer V neurons in mouse cortex projecting to different targets have distinct physiological properties. J Neurophysiol 98:3330-3340. CrossRef Medline

Herry C, Garcia R (2002) Prefrontal cortex long-term potentiation, but not long-term depression, is associated with the maintenance of extinction of learned fear in mice. J Neurosci 22:577-583. Medline

Herry C, Vouimba RM, Garcia R (1999) Plasticity in the mediodorsal thalamo-prefrontal cortical transmission in behaving mice. J Neurophysiol 82:2827-2832. Medline

Hurley KM, Herbert H, Moga MM, Saper CB (1991) Efferent projections of the infralimbic cortex of the rat. J Comp Neurol 308:249-276. CrossRef Medline

Ji G, Neugebauer V (2012) Modulation of medial prefrontal cortical activity using in vivo recordings and optogenetics. Mol Brain 5:36. CrossRef Medline

Kaczorowski CC (2011) Bidirectional pattern-specific plasticity of the slow afterhyperpolarization in rats: role for high-voltage activated $\mathrm{Ca} 2+$ channels and I h. Eur J Neurosci 34:1756-1765. CrossRef Medline

Kaczorowski CC, Davis SJ, Moyer JR Jr (2012) Aging redistributes medial prefrontal neuronal excitability and impedes extinction of trace fear conditioning. Neurobiol Aging 33:1744-1757. CrossRef Medline

Kim JJ, Jung MW (2006) Neural circuits and mechanisms involved in Pavlovian fear conditioning: a critical review. Neurosci Biobehav Rev 30: 188-202. CrossRef Medline

Knight DC, Nguyen HT, Bandettini PA (2006) The role of awareness in delay and trace fear conditioning in humans. Cogn Affect Behav Neurosci 6:157-162. CrossRef Medline

Kwapis JL, Jarome TJ, Lee JL, Gilmartin MR, Helmstetter FJ (2014a) Extinguishing trace fear engages the retrosplenial cortex rather than the amygdala. Neurobiol Learn Mem 113:41-54. CrossRef Medline

Kwapis JL, Jarome TJ, Helmstetter FJ (2014b) The role of the medial prefrontal cortex in trace fear extinction. Learn Mem 22:39-46. CrossRef Medline

Larkman A, Hannay T, Stratford K, Jack J (1992) Presynaptic release probability influences the locus of long-term potentiation. Nature 360:70-73. CrossRef Medline

Laviolette SR, Lipski WJ, Grace AA (2005) A subpopulation of neurons in the medial prefrontal cortex encodes emotional learning with burst and frequency codes through a dopamine $\mathrm{D}_{4}$ receptor-dependent basolateral amygdala input. J Neurosci 25:6066-6075. CrossRef Medline

LeDoux JE (2000) Emotion circuits in the brain. Annu Rev Neurosci 23: 155-184. CrossRef Medline

LüthiA, McCormick DA (1998) H-current: properties of a neuronal and network pacemaker. Neuron 21:9-12. CrossRef Medline

Magee JC, Carruth M (1999) Dendritic voltage-gated ion channels regulate the action potential firing mode of hippocampal CA1 pyramidal neurons. J Neurophysiol 82:1895-1901. Medline

Marshall L, Helgadóttir H, MölleM, Born J (2006) Boosting slow oscillations during sleep potentiates memory. Nature 444:610-613. CrossRef Medline

Mason A, Larkman A (1990) Correlations between morphology and electrophysiology of pyramidal neurons in slices of rat visual cortex. II. Electrophysiology. J Neurosci 10:1415-1428. Medline

McCormick DA, Pape HC (1990) Properties of a hyperpolarizationactivated cation current and its role in rhythmic oscillation in thalamic relay neurones. J Physiol 431:291-318. CrossRef Medline

McGinty VB, Grace AA (2008) Selective activation of medial prefrontal-toaccumbens projection neurons by amygdala stimulation and Pavlovian conditioned stimuli. Cereb Cortex 18:1961-1972. CrossRef Medline 
Morgan MA, LeDoux JE (1995) Differential contribution of dorsal and ventral medial prefrontal cortex to the acquisition and extinction of conditioned fear in rats. Behav Neurosci 109:681-688. CrossRef Medline

Moyer JR Jr, Brown TH (1998) Methods for whole-cell recording from visually preselected neurons of perirhinal cortex in brain slices from young and aging rats. J Neurosci Methods 86:35-54. CrossRef Medline

Moyer JR Jr, Brown TH (2007) Visually-guided patch-clamp recordings in brain slices. In: Advanced techniques for patch-clamp analysis, Ed 2 (Walz W, ed), pp 169-227. Totowa, NJ: Humana.

Moyer JR Jr, Song C (2014) Layer- and region-specific differences in the neurophysiological properties of medial prefrontal cortical neurons. Soc Neurosci Abstr 40:746.25.

Moyer JR Jr, Thompson LT, Disterhoft JF (1996) Trace eyeblink conditioning increases CA1 excitability in a transient and learning-specific manner. J Neurosci 16:5536-5546. Medline

Moyer JR Jr, McNay EC, Brown TH (2002) Three classes of pyramidal neurons in layer $\mathrm{V}$ of rat perirhinal cortex. Hippocampus 12:218-234. CrossRef Medline

Oswald MJ, Oorschot DE, Schulz JM, Lipski J, Reynolds JN (2009) IH current generates the afterhyperpolarisation following activation of subthreshold cortical synaptic inputs to striatal cholinergic interneurons. J Physiol 587:5879-5897. CrossRef Medline

Parsons RG, Gafford GM, Helmstetter FJ (2010) Regulation of extinctionrelated plasticity by opioid receptors in the ventrolateral periaqueductal gray matter. Front Behav Neurosci 4:44.

Pattwell SS, Duhoux S, Hartley CA, Johnson DC, Jing D, Elliott MD, Ruberry EJ, Powers A, Mehta N, Yang RR, Soliman F, Glatt CE, Casey BJ, Ninan I, Lee FS (2012) Altered fear learning across development in both mouse and human. Proc Natl Acad Sci U S A 109:1631816323. CrossRef Medline

Paxinos G, Watson C (1998) The rat brain in stereotaxic coordinates, Ed 4. San Diego: Academic.

Perez-Cruz C, Müller-KeukerJI, Heilbronner U, Fuchs E, FlüggeG (2007) Morphology of pyramidal neurons in the rat prefrontal cortex: lateralized dendritic remodeling by chronic stress. Neural Plast 2007:46276. Medline

Pérez-JaranayPerez-Jaranay JM, Vives F (1991) Electrophysiological study of the response of medial prefrontal cortex neurons to stimulation of the basolateral nucleus of the amygdala in the rat. Brain Res 564:97-101. CrossRef Medline

Rosenkranz JA, Grace AA (2002) Dopamine-mediated modulation of odour-evoked amygdala potentials during pavlovian conditioning. Nature 417:282-287. CrossRef Medline

Rumpel S, LeDoux J, Zador A, Malinow R (2005) Postsynaptic receptor trafficking underlying a form of associative learning. Science 308:83-88. CrossRef Medline
Runyan JD, Moore AN, Dash PK (2004) A role for prefrontal cortex in memory storage for trace fear conditioning. J Neurosci 24:1288-1295. CrossRef Medline

Santini E, Porter JT (2010) M-type potassium channels modulate the intrinsic excitability of infralimbic neurons and regulate fear expression and extinction. J Neurosci 30:12379-12386. CrossRef Medline

Santini E, Quirk GJ, Porter JT (2008) Fear conditioning and extinction differentially modify the intrinsic excitability of infralimbic neurons. J Neurosci 28:4028-4036. CrossRef Medline

Sehgal M, Song C, Ehlers VL, Moyer JR Jr (2013) Learning to learn - intrinsic plasticity as a metaplasticity mechanism for memory formation. Neurobiol Learn Mem 105:186-199. CrossRef Medline

Sehgal M, Ehlers VL, Moyer JR Jr (2014) Learning enhances intrinsic excitability in a subset of lateral amygdala neurons. Learn Mem 21:161-170. CrossRef Medline

Song C, Detert JA, Sehgal M, Moyer JR Jr (2012) Trace fear conditioning enhances synaptic and intrinsic plasticity in rat hippocampus. J Neurophysiol 107:3397-3408. CrossRef Medline

Song C, Ehlers VL, Aitken JC, Moyer JR Jr (2015) Delay fear conditioning enhances the intrinsic excitability of infralimbic neurons. Soc Neurosci Abstr 41:728.09.

Sotres-Bayon F, Diaz-Mataix L, Bush DE, LeDoux JE (2009) Dissociable roles for the ventromedial prefrontal cortex and amygdala in fear extinction: NR2B contribution. Cereb Cortex 19:474-482. CrossRef Medline

Thompson LT, Moyer JR Jr, Disterhoft JF (1996) Transient changes in excitability of rabbit CA3 neurons with a time course appropriate to support memory consolidation. J Neurophysiol 76:1836-1849. Medline

Vertes RP (2004) Differential projections of the infralimbic and prelimbic cortex in the rat. Synapse 51:32-58. CrossRef Medline

Vouimba RM, Maroun M (2011) Learning-induced changes in mPFC-BLA connections after fear conditioning, extinction, and reinstatement of fear. Neuropsychopharmacology 36:2276-2285. CrossRef Medline

Weike AI, Schupp HT, Hamm AO (2007) Fear acquisition requires awareness in trace but not delay conditioning. Psychophysiology 44:170-180. CrossRef Medline

Xu J, Kang N, Jiang L, Nedergaard M, Kang J (2005) Activity-dependent long-term potentiation of intrinsic excitability in hippocampal CA1 pyramidal neurons. J Neurosci 25:1750-1760. CrossRef Medline

Zelcer I, Cohen H, Richter-Levin G, Lebiosn T, Grossberger T, Barkai E (2006) A cellular correlate of learning-induced metaplasticity in the hippocampus. Cereb Cortex 16:460-468. CrossRef Medline

Zhang W, Linden DJ (2003) The other side of the engram: experiencedriven changes in neuronal intrinsic excitability. Nat Rev Neurosci 4:885900. CrossRef Medline 